\title{
Arquitectura: Memoria y Tributo. Espacios destinados al Recuerdo, la Verdad y a la No Repetición de la Barbarie Humana en Tiempos de Paz
}

\section{Architecture: Memory and Tribute. Spaces for the Memory, Truth and Non-Repetition of Human Barbarism in Times of Peace}

\author{
Artículo de investigación. Fecha de Recepción: 04/18/2019. Fecha de Aceptación: 05/28/2019
}

DOI: 10.17981/mod.arq.cuc.22.1.2019.09

Articulo de Reflexión producto de Investigación

Giovanni Giuseppe De Piccoli Córdoba

Universidad Santo Tomás, Bucaramanga (Colombia)

giovanni.de@ustabuca.edu.co

Para citar este artículo:

De Piccoli, G. (2019). Arquitectura: Memoria y Tributo. Espacios destinados al Recuerdo, la Verdad y a la No Repetición de la Barbarie Humana en Tiempos de Paz, MODULO ARQUITECTURA CUC, vol. 22, no. 1, pp. 219-286, 2019. DOI: http://doi.org/10.17981/mod.arq.cuc.22.1.2019.09

\section{Resumen}

La Paz... ¿ Es acaso algo que se negocia?;Acaso no es un estado propio de hombre y de su esencia como ser individual y desde su convivencia con la comunidad propendiendo a una excelente relación entre individuos que profesan diferentes formas ideológicas de pensamiento desprovista de parcialidades y apegos particulares?; No consiste por definición en un estado de derecho y deber personal y colectivo que según muchas fuentes resulta de una situación de quietud y de tranquilidad? La etimología de esta palabra de tres letras, procede del latín PAX, que se considera como "La paz se refiere a un estado de tranquilidad y seguridad... de armonía que esta libre de guerras, conflictos y contratiempos, Todos deseamos experimentarla en nuestro país y en nuestro interior... La paz es deseable universalmente y sabemos que para mantenerla es necesario ser tolerante y abierto al dialogo independientemente de nuestros valores culturales". El siguiente articulo es un análisis historiográfico de la capacidad creadora y destructora del ser humano, y como la arquitectura el arte son un medio de reivindicación que honorifica a la victima sin exaltar a victimario permitiendo que en el lugar donde hubo ausencia de paz y se motivo un conflicto, tal evento quede en la memoria comunitaria e individual de ciudadano para evitar el olvido, reivindicar a la victima y propender al nunca mas volver a repetir un acto de violencia que marco y segó en el peor de los casos vidas imposibles de reparar, pero al menos por medio del arte, la arquitectura y el diseño poderlas exaltar eternamente en la generación de espacios arquitectónicos públicos donde confluye el arte, el diseño y la arquitectura.

Palabras clave: Arquitectura; Memoria; Monumento; Comunicación Visual; Patrimonio; Paz; Pos conflicto.

\begin{abstract}
La pace... E'qualcosa che viene negoziato? Non è una condizione adeguata dell.uomo e della sua essenza come un individuo e della sua convivenza con la comunità che tende a un ottimo rapporto tra individui che professano diverse forme ideologiche del pensiero privo di parzialità e attaccamenti particolari, non consiste, per definizione, di uno stato di diritto e di dovere personale e collettivo che, secondo molte fonti, deriva da una situazione di calma e tranquillità? L'etimologia di questa parola di tre lettere, dal PAX latina, che è considerato come "La pace si riferisce ad uno stato di tranquillità e sicurezza... di armonia che è privo di guerre, conflitti e battute d'arresto, tutti noi vogliamo vivere nel nostro paese e dentro di noi... la pace è universalmente desiderabile e sappiamo che per mantenere è necessario essere tolleranti ed aperti al dialogo, indipendentemente dei nostri valori culturali". II sequente articolo è un'analisi storiografica della capacità creativa e distruttiva degli esseri umani e come l'architettura e l'arte sono un mezzo di sostegno che onorifica alla vittima, senza esaltare il vittimario permettendo al luogo dove non c'era la pace e c'é stato il conflitto, su un evento del genere, dare alla comunità una memoria eppure individuale ed evitare cosí che il cittadino, alla fine, non possa evitare dimenticare, rivendicare alla vittima e tendere a non ripetere mai più un atto di violenza che inquadra e taglia nel caso peggiore impossibile da riparare, ma almeno attraverso l'arte, I'architettura e il design possono essere esaltati eternamente nella generazione di spazi architettonici pubblici in cui convergono arte, design e architettura.

Parole guida: Architettura; memoria; monumento; comunicazione
\end{abstract} visiva; eredità; pace; post conflitto. 


\section{INTRODUCCIÓN}

Históricamente la naturaleza del ser humano debido a su complejidad psicosomática es impredecible en algunos casos y predecible en otros tantos, lo cierto es que el conflicto es inherente en nuestra especie; la herencia genética de Caín y Abel se transmite de generación en generación, transcendiendo en tiempos y espacios de modo reiterativo y como evidencia de tal afirmación resulta innegable como la historia del hombre en este mundo es una continua lucha de poder, control, abusos y perturbaciones en donde hermano contra hermano se confrontan ocasionado destrucción, muerte, hambre y desolación. En la antigüedad mas remota el hombre primitivo luchaba contra sus congéneres vecinos o foráneos por tierras, posesiones, riquezas y por el control hegemónico de una nación o tribu sobre otra, al mejor estilo de Games of Thrones, lo hacia con arcos y flechas, espadas y puñales; después de milenios de evolución y con la invención de la pólvora por parte de los chinos en el siglo IX D.C se sigue en lo mismo, sedientos de conflictos, solo que se utilizan ametralladoras, misiles balísticos y sustancias neurotóxicas...esto dice mucho sobre quien es el ser humano realmente, después de todo se continua siendo primitivos tal como en los exordios de la historia, en donde ese concepto de paz que implica respeto, justicia, igualdad y fraternidad sigue siendo una utopía.

De muchas maneras el tiempo se da su tiempo y finalmente otorga a la victima reparición; El arte rupestre por ejemplo, en las pinturas parietales de las cuevas de Altamira, Lascaux y Chauvet, la primera en la región Cantábrica y las dos ultimas en Francia, muestran escenas de combate, cacerías y situaciones cotidianas entre otras representaciones, pero el hecho de plasmarlas sobre la roca era un acto de conmemoración al animal asesinado o a los combatientes masacrados y así por medio de la magia parasimpática el alma, la energía, la forma física garantizara la repetición victoriosa del suceso y al mismo tiempo la perpetuidad del acontecimiento en honor al que ya dormía para siempre. En todas las culturas antiguas históricas hay testimonios grabados en piedra, textos manuscritos, espacios arquitectónicos, piezas de arte pictóricas o escultóricas que evidencian conflictos, victorias, verdugos y victimas, sacrificios y ofrendas, muertes y epitafios, mismos que se repiten en elementos comunicativos de un hecho bélico o desastre natural o artificial en cada época a través de los siglos hasta el día de hoy, lo que quiere decir que el hombre en su afán de registrar y contar un acontecimiento negativo o positivo deja un vestigio inteligible que como manifiesto diga « Aquí ocurrió esto...no se olvide y no se repita.... sin embargo, ese efecto declaratorio en muchos casos es ignorado por las generaciones venideras. Quizás una forma de concientizar a la comunidad mundial sobre los acontecimientos que han convulsionado la historia del hombre y que esos eventos no ocurran nuevamente es una respuesta que desde la arquitectura, desde el concepto del monumento o memorial, como registro visual y táctil, se interviene un lugar 
dentro de un espacio publico o un paisaje creado por los arquitectos, diseñadores y artistas generando un sitio de concentración donde todo aquel que desee puede acceder y por un breve momento; viviendo, recorriendo y admirando de modo interactivo ese espacio creado, logra establecer un vinculo entre el pasado, el presente y el futuro y así dar tributo al recuerdo de un hecho que a manera de conmemoración a las victimas genere empatía por ellas y rechazo hacia el factor victimizante que en opresión causo la perdida para poder en ese acto espacial y materico del objeto arquitectónico, plástico y con concepto de diseño se genere por medio de él, tejido humano, conciencia social y cultura ciudadana.

Este articulo busca de alguna forma dar a conocer algunos de esos productos de conmemoración en donde las disciplinas del arte y la arquitectura, junto con el diseño, propenden a involucrar al hombre dentro de una comunidad que valore los sacrificios hechos por otros, siendo sensible a una realidad que eventualmente no los toca directamente aunque si indirectamente y al mismo tiempo da la oportunidad de conocer una historia que si... en la mayoría de los casos es triste y dramática ya que a veces la realidad, aquella que no se vive, supera la fantasía. Solo la arquitectura y el arte en sus múltiples manifestaciones tiene ese poder de comunicar y quizás si se entienden esos diálogos universales, se puede ser menos indiferentes ante estos crímenes contra la humanidad y sumarse a la voz del lenguaje, el símbolo y el significado trasmitido por un objeto arquitectónico y de arte que no dejara en mutismo a aquellas voces que fueron silenciadas. Desde la tesis de maestría del autor, un capitulo entero se trato el tema de como desde las disciplinas del arte, el diseño y la arquitectura se busca de muchas maneras un bien y un objetivo social, y por medio de un ejercicio investigativo se hace la reflexión desde la academia y en este caso desde las Instituciones de Educación Superior de como un modo de connotar las realidades contemporáneas en donde la violencia, el terrorismo, el abuso de poder son platos del día a día es posible abordar desde la visión de tales disciplinas los hechos que se dieron y se siguen dando con el fin de narrar una historia a las generaciones por venir para que no olviden y no repitan los errores de sus antecesores.

\section{La historia de la inequidad humana en 7 ejemplos}

La historia antigua y reciente del ser humano desde una observación personal como historiógrafo y desde lo muy particular de quien escribe, se establecen 7 episodios deplorables que han quebrantado todos los valores que diferencian al ser humano de la animalidad, haciendo que el hombre se transforme en un ser monstruoso y abominable, un termómetro que sube y que mide la capacidad aniquiladora de este ser bípedo, el máximo predador, aquel que se ubica en la cima de la cadena alimenticia y se ubica en el vértice de la pirámide de poder impartiendo en algunos casos dolor y sufrimiento: ¡El ser Humano! Esos episodios están 
marcados por tres aspectos, uno de ellos es que fueron capaces de turbar el orden mundial por la atrocidad desaforada desde el sujeto de poder y el sujeto subyugado bajo ese poder; el segundo aspecto es que como de costumbre en estos hechos barbáricos, no hay distinción de genero, raza, condición social o credo religioso, todos sufren por igual; y el tercer aspecto quizás el mas detestable es que si bien ahora se conocen los hechos, en su momento pudieron haber sido evitados, si y solo si, en el antes de ser cometidos alguna voz de condena, de rechazo, de negativa se hubiera sumado a otras voces que juntas, hubiesen marcado una diferencia...pero no fue así.

En primer lugar, la erradicación de los pueblos indígenas americanos en todo el continente desde Alaska a la Patagonia, por parte de los conquistadores y colonizadores procedentes de las antiguas coronas europeas. Un articulo publicado por $\mathrm{Pa}$ checo (2002) menciona:

Las cifras en cuanto a número de habitantes en América siguen siendo un campo de polémica. Los historiadores hispanistas aseguran que la población indígena era de 11 a 13 millones en el tiempo en que ocurrió el descubrimiento; cifra calculada por el investigador Rosenblat en 1954. De otra parte, la corriente indigenista, sobre todo de la escuela de Berkeley, da la cifra de entre 90 a 112 millones. No obstante, nuevas ponderaciones hacen suponer en el presente que en América existían unos 80 millones de habitantes hacia 1492. De esta cantidad, las tres cuartas partes (unos 65 millones), corresponderían al territorio que luego fue Hispanoamérica. Sus grandes centros poblacionales eran el imperio inca, con cerca de 30 millones, y el mexica con unos 20.
Pues bien, hacia 1700, siglo y medio después, este total se había reducido de manera dramática a cinco millones; lo que representa la desaparición de 60 millones de indígenas, unos 400 mil cada año. Estas cifras se pueden comparar con el número de muertos resultado de la segunda Guerra Mundial. De esta conflagración tampoco se tienen cifras exactas en cuanto a los decesos. Sin embargo, la ONU hace un balance de este modo: 50 millones de muertos en total, entre los que cabe destacar a la Unión Soviética con 20; Alemania, 7; Polonia, 6; Japón, 2; y 1.5 corresponderían a Yugoslavia (2002)

En segundo lugar, la matanza de la noche de San Bartolomé, en París, una ciudad anti protestante. La madre del rey Carlos IX, Catalina de Medici, uno de los 7 grandes personajes del renacimiento convenció a Carlos IX a iniciar un exterminio progresivo de los hugonotes y este, siguiendo su cruel consejo promulgo la masacre que en tres jornadas, desde la madrugada del día de San Bartolomé el 24 de agosto de 1572, el hecho que quedo registrado en la historia Universal se extendió por toda Francia cobrando según fuentes varias, la vida de 12000 protestantes que fueron baleados, descuartizados, quemados vivos, degollados y sometidos a toda clase de vejaciones. En tercer lugar, otro episodio que conmueve aun hoy en día a la humanidad fue el genocidio del pueblo Judío por parte del Nazismo: el Holocausto que desde 1941 hasta 1945 bajo el nominativo de la «Solución Final», 2.700 .000 millones de almas aproximadamente fueron apagadas paulatinamente en los campos de concentración, en 
fusilamientos, cámaras de gas y trabajos forzosos muriendo además por inanición y frio. El cuarto lugar son las detonaciones de las bombas atómicas de Hiroshima y Nagasaki, En agosto de 1945. Japón, se convertiría en la única nación, que hasta la fecha ha sufrido en carne propia una bomba nuclear y sus estragos en donde mas de cien mil personas fueron vaporizadas y quemadas instantáneamente con la fuerza desbastadora del átomo y su energía liberada equivalentes a 15000 toneladas de TNT, muchos mas, cientos de miles, murieron lentamente por los efectos de la radiación y otros tantos, producto de la misma, nacieron con malformaciones y mutaciones genéticas en el transcurso de 20 años.

En cuarto lugar, en épocas mas próximas, a finales del siglo $X X$, otras masacres se dieron en el planeta, la de Ruanda, el 6 d abril de 1994, mas de un millón de personas fueron masacradas a punta de machete y hachas diezmando la población masculina del lugar y dejando a mas de 200.000 mujeres marcadas de por vida ya que fueron violadas o mutiladas por conflictos étnicos y religiosos de dos tribus locales, los Hutus y los Tutsis. En quinto lugar, casi paralelamente en esos años, en Europa se llevaba a cabo la Guerra de Bosnia, 1992-1995, que terminó en un genocidio por limpieza racial musulmana con 8373 personas asesinadas entre hombres, niños, mujeres y ancianos y las de otros 8000 desaparecidos. El sexto y el séptimo lugar, no son propiamente unos referentes puntuales dado en algún rincón del planeta, no obstante son dos de los flagelos que muestra la crueldad del ser humano incluso, en tiempos de paz, el primero de ellos, la esclavitud. Las victimas de la esclavitud se cuentan por millones, establecer un numero desde los tiempos mas remotos seria como contar los granos de arena en el desierto o las gotas de agua que conforman los océanos, seria contar las hojas que se lleva una borrasca o las chispas que salen en una hoguera encendida que arde por horas. Imposible establecer un numero pero fuentes recientes y específicamente Notiamerica (2019), una publicación madrileña manifestó lo siguiente en relación al día 25 de Marzo, día internacional del Recuerdo a las Victimas de la Esclavitud:

Hoy se honra la memoria de millones de victimas de la esclavitud, durante mas de 400 años, mas de 15 millones de hombres, mujeres y niños fueron victimas de la deplorable trata trasatlántica de esclavos, uno de los capítulos mas negros de la historia de la humanidad, es por ello que cada 25 de marzo se celebra... con esta efeméride, la conmemoración del sufrimiento...la memoria de los héroes que se opusieron a este crimen masivo contra la humanidad pretendiendo renovar la promesa de velar que ningún ser humano vuelva a ser tratado jamás como mercancía (2019).

Pese a las intenciones recurrentes en los 5 continentes por frenar esta problemática social y económica, lastimosamente este látigo sigue azotando de manera reiterativa las sociedades contemporáneas incluso aquellas mas desarrolladas. Es bien sabido que la trata de personas se esta dando ahora en los episodios migratorios en 
Hispanoamérica, las caravanas de migrantes de centro América, procedentes de Honduras, las que salen de México manejadas por los «coyotes" un nombre apropiado para estas "bestias humanas" que trafican con niños y mujeres especialmente, y aquellas que acontecen con el éxodo de venezolanos a los países vecinos son un testimonio veraz de que en pleno siglo XXI sigue existiendo esclavitud. No se podría dejar de mencionar la Trata de Blancas, en artículo recuperado de el Mostrador (DW, 2018), donde se explica de una manera sintética lo que ocurre con este fenómeno que rebasa fronteras de la siguiente forma.

El tráfico ilegal de personas es un negocio criminal que podría haber superado al tráfico ilegal de armas y drogas. La OSCE instó a los países miembros a contabilizar las víctimas de ese delito. La trata de blancas es una de las principales fuentes de ingresos de la criminalidad organizada a nivel mundial. Según estimaciones de la Organización para la Seguridad y la Cooperación en Europa, OSCE, el tráfico ilegal de seres humanos podría ya haber superado al de armas, al haber alcanzado en el 2005 un volumen de negocio superior los 32.000 millones de dólares anuales, un negocio en el que son explotados 2,5 millones de personas. La mayoría de las víctimas son mujeres y niños que caen en manos de criminales sin escrúpulos. Son explotados sexualmente y obligados a trabajar en condiciones de esclavitud. Se estima que más de la mitad de las víctimas son menores de 18 años y no hay país que se salve de esta moderna forma de esclavitud (DW, 2018).

Por otra parte, el mismo articulo afirma que:
La mayoría de las víctimas provienen de estratos marginales y la explotación sexual no es la primera forma de violencia que viven en carne propia. Es por ello que distintas organizaciones proponen iniciativas para atacar el problema de raíz. Lo más importante es informar y sensibilizar a las víctimas potenciales y ofrecerles alternativas. Las víctimas no tienen alternativas en su país de origen, pero son los países destino, en donde por lo general hay poco interés en este tema, quienes dictan las reglas del mercado, afirma Eva Blaudet, la representante especial de la OSCE para la lucha contra el tráfico de personas. Blaudet, instó en Viena a los 56 países miembros de la organización a crear mecanismos que contabilicen el número de víctimas de ese delito pues para combatir el problema de manera eficaz es necesario armonizar las estadísticas nacionales sobre el número de víctimas. Según el Fondo de las Naciones Unidas para la Infancia (UNICEF), en el 2001 hubo 1,75 millones de personas afectadas (DW, 2018).

El séptimo: El Terrorismo, se vivió de manera mas impactante en los inicios de la primera década del siglo XXI, justamente el 11 de septiembre de 2001, los atentados a las torres gemelas del World Trade Center (Nueva York, USA), seguido por los ataques al pentágono en Washington en el mismo país, y los sucedidos en 11 de marzo de 2004, al metro de Madrid (España) y de igual manera el 7 de julio de 2005 en el metro de Londres cobraron un numero representativo de victimas en cada uno de ellos, solo en el corazón financiero de Nueva York, según varias fuentes el numero fue de 3016 incluyendo los desaparecidos:; esta plaga que desbasta naciones y se incrementa cada día mas. 
La revista Infobae en su edición del 14 de abril de 2019, presento un completo informe al respecto afirmando que:

En 2016 se registraron 25.673 muertes por atentados terroristas en el mundo, un $21 \%$ menos de los 32.685 fallecidos en 2014 -cuando se alcanzó un máximo en las cifras tras cuatro años de incrementos- y un 13\% menos respecto a 2015. Estamos viendo una tendencia enormemente positiva a nivel global. Creemos que es un potencial punto de inflexión en la lucha contra el terrorismo", afirmó el director de Investigación del IEP, Daniel Hyslop, que resaltó el retroceso del extremismo radical islamista. todavía hay tendencias inquietantes, ya que más países que en cualquier otro momento de los últimos 17 años sufrieron por lo menos una muerte causada por el terrorismo. En total 77 países sufrieron por lo menos una muerte causada por el terrorismo, más que los 65 de 2016, dando lugar a que la puntuación general del GTI, que mide el impacto del terrorismo, se deteriorara el 4\% con respecto a 2015 (Infobae, 2019).

Estos 7 episodios que narran la bajeza del ser humano no están tan lejanos de la realidad nacional, en Colombia. La revista Portafolio (2017), muy recientemente, menciona que "el conflicto armado en Colombia a afectado directamente a 8.376.463 personas". Una situación de guerra interna durante mas de 52 años que en teoría finalizo con los acuerdos de paz del 24 de noviembre de 2017". De igual manera dicho articulo menciona las siguientes cifras (Portafolio, 2017):
A propósito de la conmemoración, el Congreso de la República llevó a cabo una sesión en la que se escucharon a 35 representantes de las víctimas. Según el Registro Único de Víctimas (RUV), de los 8.376.463 afectados 8.074.272 corresponden a "víctimas del conflicto armado" y las otras 302.191 a la categoría "víctimas sentencias", que fueron incluidas en cumplimiento de una sentencia que hace alusión a la «atención, asistencia y reparación integral" de quienes han sido perjudicados por el "conflicto armado interno". Asimismo, ese despacho precisó que de las 8.074.272 víctimas, 7.134 .646 son casos de desplazamiento, 983.033 homicidios, 165.927 desapariciones forzadas, 10.237 torturas y 34.814 secuestros, entre otros hechos. «Son las víctimas las protagonistas de este proceso de paz. Con derecho a la verdad, convivencia y no repetición. No queremos una víctima más en Colombia..

Lo anterior quizás es algo que se desconoce, lastimosamente el ser humano esta ajeno al dolor del otro y solo se percata de ese sufrir cuando lo vive en su propia existencia y está en los zapatos del otro, literalmente. la condición humana hacia la negación es un hecho, que no es otra cosa mas que no darle importancia a cierta situación desagradable y continuar la rutina cotidiana como si dicha situación no existiera hace que el ser humano se haga insensible a su propio entorno por lo tanto, apático al contexto de los demás, desasociándose de cualquier tipo de empatía o proximidad a quien por alguna situación esta pasando por un momento difícil. El que como especie no tengamos afecto y emoción hacia ciertos hechos dolorosos 
permiten que se incurra en repetir los errores de la historia, el no reparar el daño causado y condenar al olvido uno o varios acontecimientos que requieren de ser recordados para ser valorados no por el dolor causado sino por el grado de sobrevivencia ante un magnicidio que da prueba del carácter, la fortaleza y la capacidad de seguir la vida sin rencor, del sobreviviente, sin remordimientos y sin el dolor que si bien sigue de alguna forma en el cuerpo y en el alma este debe ser un impulso para continuar adelante y en lo posible como se suele decir « voltear la pagina"

\section{La mediación y la narrativa de la} arquitectura y el arte como mensaje de rechazo a conflictos universales en tiempos de guerra y tiempos de paz

En el mundo de la arquitectura y el arte de muchas maneras se logra mostrar situaciones de conflicto a lo largo de las sociedades en donde estos se presentan rompiendo barreras y fronteras tanto físicas como de pensamiento puesto que al fin y al cabo, donde sea que el conflicto exista, la temática será igual: un ser humano atrapado en el dolor de una guerra que le quita cualquier derecho de vivir en paz, con su nación y consigo mismo. En relación a la arquitectura que aglutina en su praxis; cultura, sociedad, historia y memoria, además de las otras bellas artes en si misma, no esta ajena a la exaltación matérica de un episodio dentro de una sociedad que merite de alguna manera hacer honor, rendir un tributo, dar un homenaje hacia las victimas que estuvieron involucradas en esos episodios obscuros de la comunidad en cuestión, generando objetos matericos que inmortalizan en un ente arquitectónico o pieza de arte, con ciertas características estéticas y simbólicas en su lenguaje narrando una historia desde la perspectiva de la victima para que quede un testimonio para que no se repita, se condene y se vivencie el hecho buscando la reparación anecdóticamente a aquellos que sobrevivieron y que murieron en el conflicto instalándose en la memoria individual y colectiva de toda la comunidad que debe reconocerse en ellos y no actuar en negación a un hecho que puede pasarle a cualquiera y en cualquier momento, con mayor razón hoy, donde el mundo esta tan convulsionado y la $\mathrm{Paz}$, parece ser un bien de consumo que escasea cada vez mas.

En el articulo "La comunicación y el arte", las ilustraciones que se levantan para llevar un significado de inconformidad pacíficamente, del 12 de febrero de 2019, el autor, quien es columnista y consultor en temas de arte, arquitectura y diseño en la reconocida revista de opinión, Enfoque Caribe, manifiesta de manera muy concreta esta función social que cumplen estas disciplinas en las sociedades contemporáneas haciendo una reflexión sobre el papel denunciador que posee el arte como expresión hacia hechos que atacan a la humanidad en general, en dicho articulo menciona: 
El arte como es una actividad exclusivamente humana que tiene como fin único comunicar. Hoy en día el arte en sus muchas manifestaciones es un medio de protesta y de documentación de los aspectos negativos de esta humanidad hoy tan trivial y por que no, ajena al dolor...esa frase fría y apática: "Mientras no me pase a mi, todo esta bien" deja mucho que decir de nuestra humanidad y precisamente algunos artistas hoy, son las voces que hablan por esos muchos labios que se han visto obligados a cerrarse y permanecer en el silencio a pesar de las injusticias (De Piccoli, 2019).

Igualmente en otro articulo, en la misma revista hace referencia a la magnitud que tiene el arte como catarsis de un conflicto y la proximidad que genera hacia la comunidad desde lo emocional y espiritual para que esta de manera simbiótica se conecte con el hecho del conflicto pero también del post conflicto. En el articulo, "La espiritualidad en el arte", la esencia del ser humana transformada en las mas grandiosas obras publicado en noviembre de 2017 hace mención al poder comunicativo del arte y como el ciudadano se vincula con la situación problemica de la siguiente manera:

Admirar una pieza de arte es entender la percepción del artista en su contexto histórico y en su entorno inmediato que le permite crear dicha pieza; por lo tanto, se ve enriquecida de matices sociales que dieron la inspiración o la pauta para ser realizada, ya que en su proceso de divulgación -porque arte es comunicación-, las connotaciones de dichos mensajes visuales no quedan solo en manos del artista, del crítico o del museo. Por el contrario, el arte, como un bien de todos, es cultura, y esta es, en sí misma, un bien social; por lo cual, siendo hoy la cultura parte de una comunidad de tipo global, es también educación. 'La Gorda Gertrudis' de Fernando Botero, en la Plaza Santo Domingo en Cartagena de Indias, no es solo una pieza de bronce; en el imaginario colectivo, en la apropiación que la comunidad nativa o foránea realiza de la escultura, tocar sus senos o sus nalgas le asegura a las parejas que tendrán un romance perdurable. Lo mismo sucede con las 'Alas de México', otra escultura pública en la Ciudad de México, realizada por Jorge Marín y ubicada en el Paseo de la Reforma.

Está hecha de bronce y tiene una versión llamada 'Alas de Paz' elaborada con el metal fundido de más de 3 toneladas de armas como producto de un programa de desarme voluntario. Esta última, es un fenómeno popular, pues más de cincuenta millones de personas se han fotografiado en medio de tan singular obra que posee un significado mucho más profundo, y las personas dicen sentir, cuando están en medio de ellas, un "halo angélico de paz y libertad". Lo anterior, denota que muchas de las manifestaciones artísticas transmiten mensajes más allá de lo que a simple vista evidencian (De Piccoli, 2017)

El arte y la arquitectura como comunicación, son el recurso mas táctil y veraz de permitir una recordación, rendir un tributo y en general proporcionar exaltación al sobreviviente, no como victima sino como victoria. Existen en la contemporaneidad muchos artistas plásticos desde pintores a escultores, que por medio de su arte muestran el conflicto; la revista Arcadia, en el 2012, selecciono las 10 obras en la historia del arte que a través de su 
mirada y su sentimiento los artistas plasmaron los conflictos y la carencia de la paz: las obras seleccionadas fueron: La muerte de Sucre (1835) de Pedro José Figueroa, los fusilamientos del 3 de mayo, de Goya, El Guernica de Picasso Violencia de Alejandro Obregón entre otras, pero una en particular la cual tuvo el autor la oportunidad de sentirla a vivo y a directo fue: La Victoria Guiando al Pueblo (1830) de Eugene Delacroix en el Museo del Louvre, en Paris Francia.(Figura 1)

Esta pieza de arte muestra las atrocidades de la guerra, en un primer plano, tres cuerpos casi descompuestos y rígidos hacen referencia a casi gilidad de la vida, aquella que es arrebatada sin importar la edad y el genero el cuerpo a la izquierda es un hombre semidesnudo, sin pantalones, exes un hombre semidesnudo, sin pantalones, exponiendo su fraglidad, su humatidad volada, su rayo de luz que ilumina fugazmente su pecho y su bajo abdomen quizás haciendo referencia al atma que ya abandono el cuerpo hace mucho; una ma que ya abre curce cue fo hace mucho, una se pierce entre el humo de una Francia en llamas, entre escombros, una figura ajena a la escena se arrastra hia los cuerpos tendidos y mira fijamente el horror de la guerra y la degradación de un cuente inerte ýn la gudo quizás visulizando su propio fin co conio fin, aque ce se ninna hacia ella como simbolo de esperanza, por que al parecenza por que lo tir aquella fe ciega que nunca se pierde, pons $\mathrm{par}$ de las victimas que esperan obterer Justicia. La

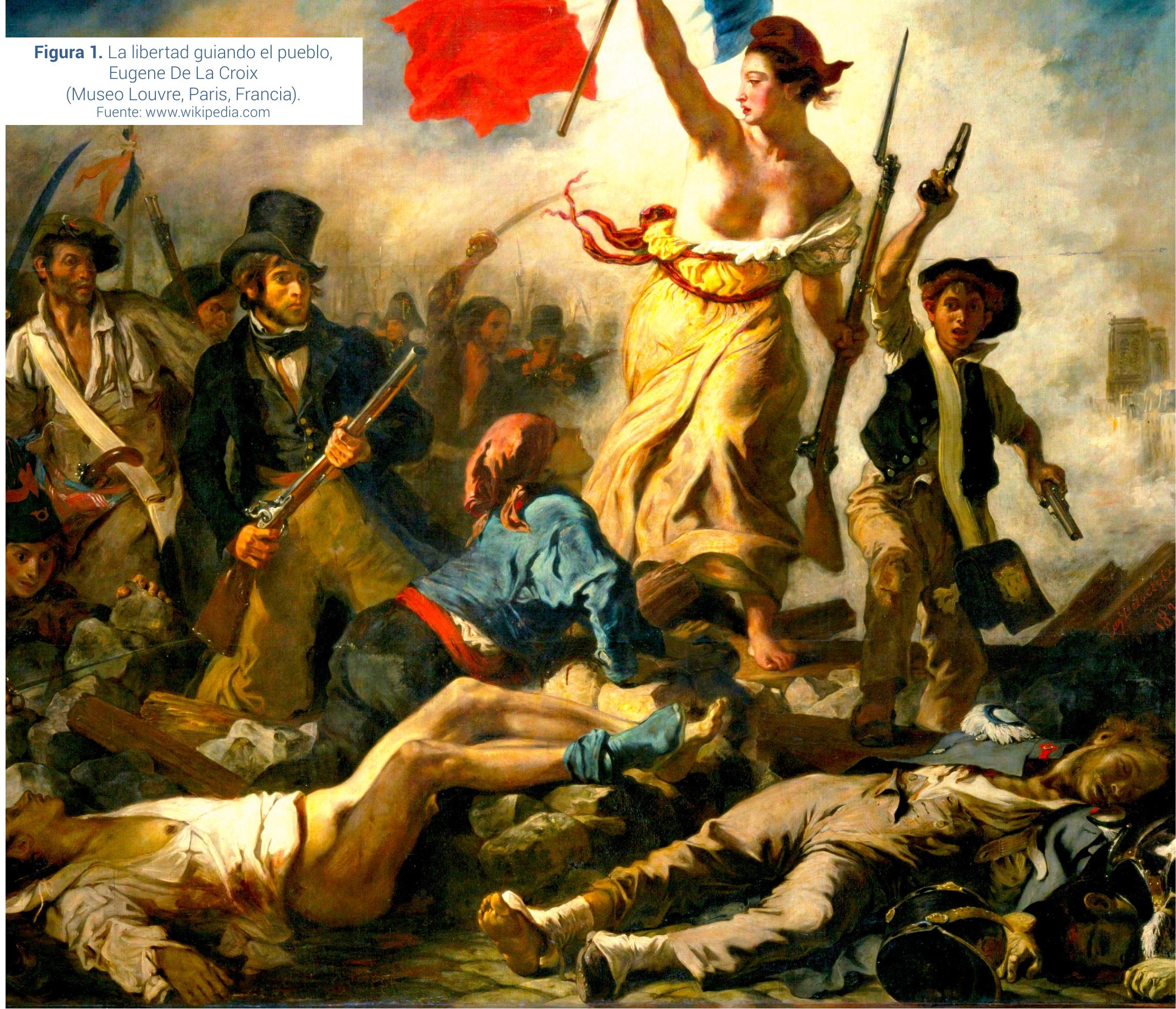

escena en general, muestra a un pueblo todo por igual, sin diferencias sociales y económicas que siguen a la victoria, a la mujer...esto es lo mas sorprendente, es el único personaje femenino, y esta pletórico de fuerza y valentía, guía al pueblo armada del fusil y esgrime una bandera tricolor su cuerpo extrañamente muestra los cánones de la belleza viril grecolatina, su brazo es musculoso y firme porta el sombrero frigio y su perfil, casi hierático inexpresivo y férreo la coloca en un plano superior rodada de un halo como un escudo impenetrable que protege a toda la nación a pesar de esta expuesta, semidesnuda del torso para arriba está dando un toque de inocencia también puede ser un símbolo hoy en día de todas esa mujeres que un suren de modo mas directo las inclemencias de conflicto en cierta forma, las mujeres llevan la peor parte, como en Ruanda o en Bosnia-Herzegovina tantas fueron ultrajadas y aun así mantuvieron su dignidad en medio de la indignidad de sus captores y la carencia de indignación de la sociedad que permitió tantas atrocidades La inocencia también se ve fragmentada en el niño, aquel que también esta armado la guerra no tiene edad, los niños son el futuro, una nación en guerra es una nación que pierde su futuro, las mujeres y los niños son las victimas mas vulnerables, este cuadro, esta pieza magistra habla después de todo de, esperanzay de fortaleza, aquella que no se fragmenta si se cree en que la justicia a veces tarda pero llega.

El diario El Tiempo (2016), hizo una semblanza El diario El Tiempo (2016), hizo una semblanza sobre una exposición llamada. Conflictos globales, manera: 
Asi lo plantea una exposición colectiva con siete ar-

tistas de varios países, que se inaugura el sábado en Lo hace a partir Contemporáneo de Bogota (MAC). te todos nos hemos planteado: "¿Por qué América Latina parece ser un territorio atrapado irremediaAquí caben el conflicto armado, el narcotráfico, la explotación de recursos naturales por medio de las multinacionales, la politica y la desigualdad social, entre otros temas. El curador del MAC, Juan David Quintero, invitó a los colombianos Fernando Pertuz, María Sánchez (México), Catalina Mena, Francisco Peró (Chile), para que expusieran piezas que geneFernando Arias, el contexto es el Chocó. Arias, quien trabaja en este departamento con su fundación Más Arte, Más Acción, identificó cómo en este lugar las al mismo tiempo, suelen desconocer sus derechos

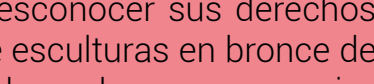
soldados vestidos y otros desnudos, como una invitación a dejar las armas y mostrarse como seres humanos (EI Tiempo, 2016) (Figura 2).

La Universidad de Málaga, con su revista ASRI, Arte y Sociedad, Revista de Investigación, publicó un articulo bastante sencillo pero muy puntual sobre las problematicas conflictivas en los países hispanoamericanos en donde las tribulaciones en relación a conflictos armados, politicas de represión y dictaduras, diferencias socio-culturales avasallais mande la gran mayoria de la poblacion vive en condiciones minimas dentro de los estándares de calidad de vida son una miscelánea de factores que llevan a la violencia que de hecho se inicia desde lo
Figura 2. Paras, Fernando Arias, Bronces
Fuente : wwwlluseduardocastillofundiciones com

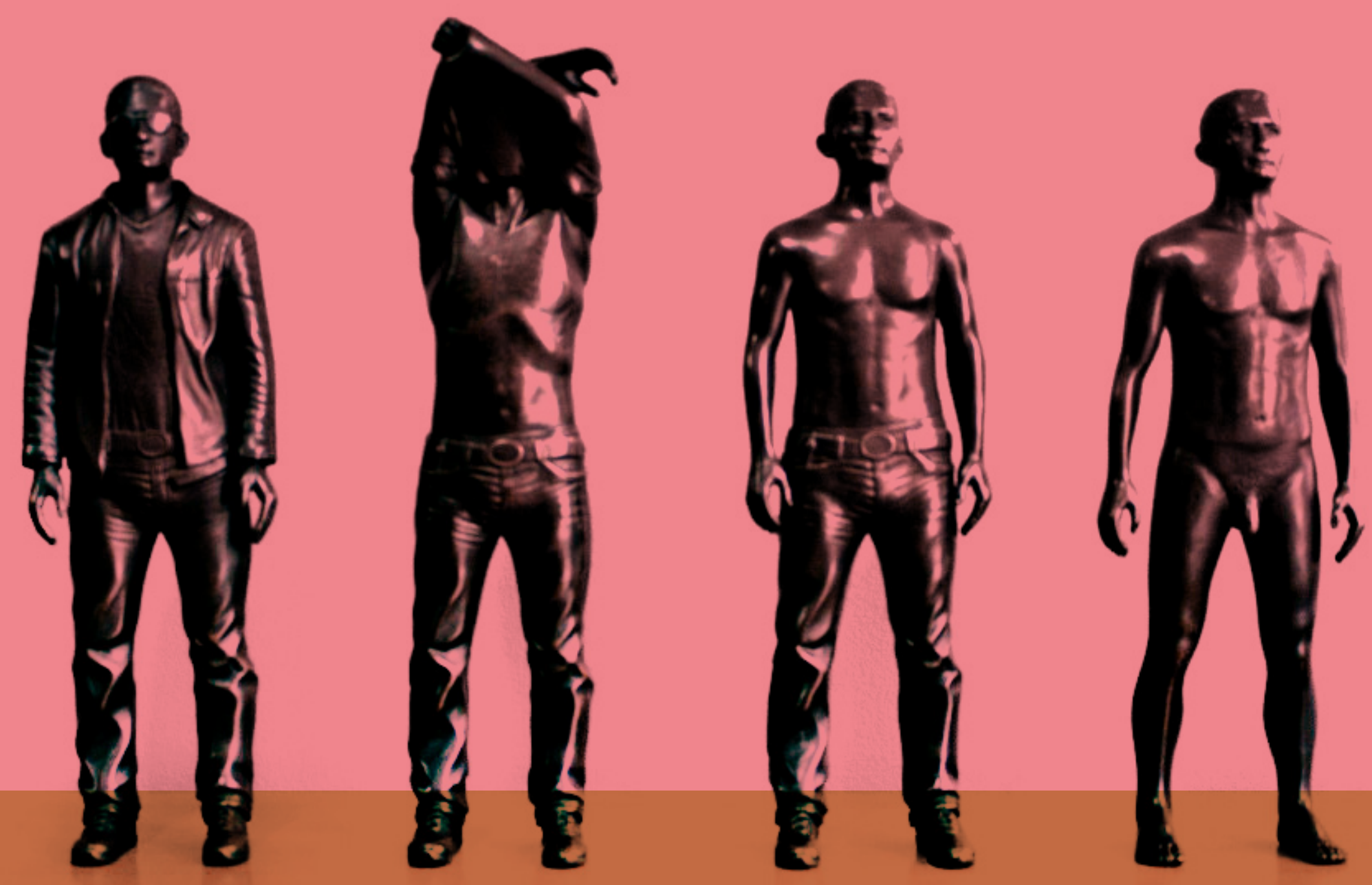

intrafamiliar y va transcendiendo a las comunidades barriales, la ciudad entera y en terminos generales, el país. El artículo procede la la Facultad de Artes de la Universidad Central del Ecuador y su autor es Juan Ramón Barbancho. Este inicia su documento con una frase de Varela J y Alvarez Uria F, tomada del libro Materiales de Sociología del Arte, Siglo XXI, Madrid.

Barbancho (2014), afirma que:

Este activismo artistico en América Latina se ha maiffestado en modos de producción de formas estétcas y de relacionalidad que anteponen la accion social a la tradicional exigencia de la autonomia del arte y desde luego totalmente alejado de aquel "arte por el la institución artística, en muchos casos controlada por el poder, y diluyen el concepto de autor/a en un hecho colectivo de acción social/política/artística, pero poco importa que sea considerado arte o no. No diferencia a artistas de no artistas. Muchos/as ya cionalmente se le ha ido dando, más bien se sienten cómodos/as con e papel de mediadores/as o posibilitadores/as. Lo "artístico" está en que provienen del mundo de la creación estética y se aprovechan de su capacidad y experiencia como organizadores/ as visuales para buscar información, documentarla y comuicarla, para hacer del arte una practica ubicada en el intersticio de orros tentorios. El ser artisesa función y su experiencia. Su finalidad es social/ política de concienciación, no la producción de "objetos", más bien lo que se produce es la acción, más claramente que nunca, de un "estar juntos" que diría Bouriaud y el aclivistio artistico busca una transfor- 
En ese orden de ideas otra pieza de arte que refieja el reclamo social por med puesta en escena de las enajenaciones que ocasionan ese desequilibrio de la paz y la buena convivencia en un entorno latinoamericano es el reconocido mural del hombre en llamas del Mexican Jose clemente Orosco ubicado el el Instituto Cutural Hospicio Cabañas, Patrimonio Unesco de Humanidad, ubicado en la ciudad de Guadalajara (Jalisco, México). (Figura 3) la experiencia espacia es maravillosa, su arquitectura neoclásica con toques tardíos barrocos juega con la teatralidad de monumento patrimonial entre la luz y la sombra lo que le brinda una atmosfera vibrante y altamente sensorial. Ya bajo la cúpula del ingreso al recinto $\mathrm{s}$ pueden apreciar en toda su magnitud los colosales murales, el Hombre en llamas, es considerada obra magna del arte mexicano por muchos especialistas en el arte, un fresco de 11 metros de largo y a 27 metros desde el suelo se puede observar en 360 grados en todo su esplendor; es la representación del periodo prehispánico azteca en donde la sangre de los rituales de sacrificio hacían parte de la civilización precolombina, sin embargo esta conectada dentro de la contemporaneidad con situación social y cultural de México y la violencia de los carteles de la droga, la inseguridad en las ciudades la corrupción y la carencia de oportundades laborales y condiciones mas humanas $d$ vida.

Las figuras de los tres hombres desnudos de cuerpo entero

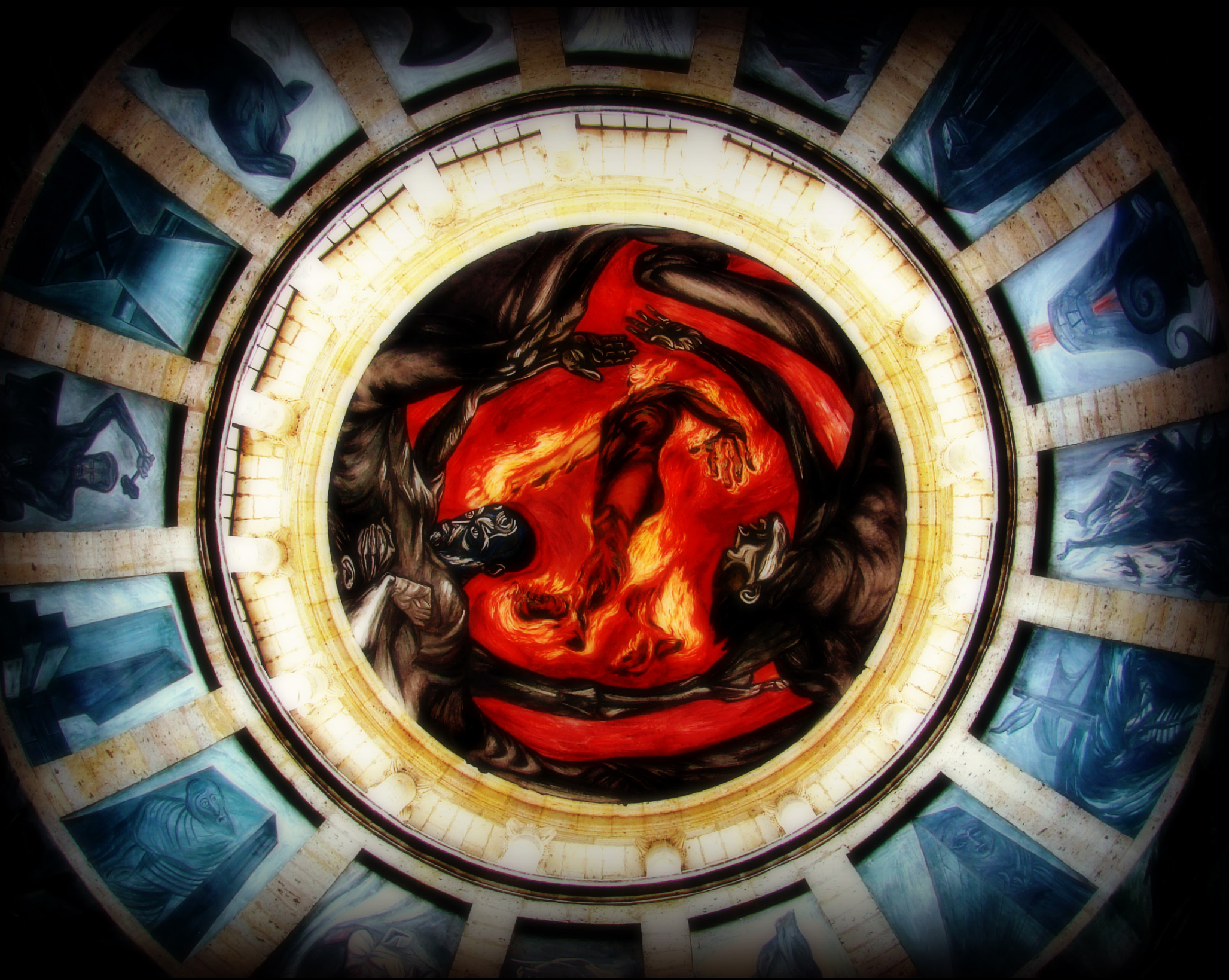

Figura 3. Mural Hombre en Llamas, Hospicio Cabañas, José Clemente Orosco (Guadalajara, México) tantes, sus rostros evidencian el sufrimiento, e horror y lo macabro de la vida cuando la paz esta ausente y la barbarie esta presente. las tres figuras que encierran al hombre en llamas ausentes de color, en tonos grises son sombras que asechan como almas que no encuentran reposo, atrapadas entre este mundo terreno y e ultra terreno, en la actualidad podrían considerarse como la tortura, podrían representar a los desaparecidos, miles de ellos que después de decenas de años son encontrados en sepulturas colectivas y clandestinas cuya memoria borro e tiempo, o también, el limbo de la justicia que mas que ciega, esta sorda y muda ante los crímenes que se comenten a diario en este país y en otros tantos de América latina. Justo en el centro se alza este cuerpo como una antorcha humana quizás una alegoría lejana del método de tortura de la organización criminal del Chapo, meter a la victima arrodillada y atada dentro de una llanta de carro a la cual versándole gasolina arde junto con el cuerpo. Siendo optimistas, el hombre el llamas también podría representar el triunfo de la luz sobre las tinieblas, la justicia sobre la impunidad el triunfo de las victimas que se alzan y son escuchadas versus el silencio impuesto que apaga todo fuego de reclamación y protesta.

Como bien se manifestó en precedencia uno de los actos incomprensibles y no aceptados dentro de una sociedad desarrollada cometidos por un grupo de personas e incluso una sola en contra de un ser individual o comunidad es el Terrorismo 
este es una constante que se repite en diversas partes del globo terráqueo y en los últimos años se hace tan frecuente que se convierte ya en un habito escuchar de masacres a estudiante dentro de su recinto escolastico, francotiradore asesinos que disparan indiscriminadamente hacia blancos aleatorios a hombres, mujeres niños en una calle, a la salida de un concierto o en un restaurante, vehículos que arrastran todo velocidad a cua lquiera que este en su paso tiroteos dentro de mezquitas incluso en lugares que no tienen conflictos de religion o credos como Nueva Zelanda o de manera mas cercana, el carro bomba registrado a las 9 y 32 de la mañana en la Escuela de Policia General Santander, en ciudad de Bogota-Colombia el 17 de enero de 2019 y que dejo un total de vidas cegadas de 21 fallecidos incluyendo el perpetrador y mas de 200 heridos. Estos actos repudiados por toda comunidad nacional e internacional en alguno casos son tan atroces que requieren algo mas allá de una noticia en los noticieros del mundo o locales, palabras de condolencias por parte de vaticano o los gobiernos en persona de jefes de estado, de marchas multitudinarias por la paz que invitan a la sana protesta y a clamar por justicia pronta y severa. Es ahi, cuando el estado propone establecer un sitio, un lugar, un espacio y por medio de un objeto artístico y/o arquitectónico por pequeño o grande que sea, lo cual es relativo, tiene como función recordar para reparar y no repetir.
Lo dramático o no del monumento dependerá de la carga emocional del artista o del arquitecto, y depende de este factor icónico, como la propuesta puede ser muy tradicional o por el contrario desde lo conceptual, muy dinámica e interactiva. El monumento a las victimas del comunismo en República Checa, ubicado en el monte Petrin, en el barrio Mala Strana es un conjunto escultórico de 7 figuras antropomorfas en metal que a manera de cuerpos sin vida descienden por la escalera del parque, los cuerpos aparecen mutilados, con cavidades y oquedades con una expresion claramente triste y desesperada, sus rostros son los matices de la desgracia que impactan por su sencilez pero su mensaje es ciertamente contundente cuándo la luz se filtra en secuencia y en la larga noche del rey obscuro, el so del radiante nuevo día vence las tinieblas (Figura 4). En ese estilo figurativo de la corporeidad humana levada a su transformación según la visión del artista que retoma el cuerpo como elemento plástico de denuncia y simbolo de su fragilidad y al mismo tiempo su fortaleza, la dualidad que podría simular loble moral de la justicia, la confrontación entre o tenebroso y lo luminoso del ser humano, el bien y el mal, en fin, esa naturaleza dual de la existencia del ser humano algunos artistas han querido plasmar en su propuesta comunicativa la exploración de estos elementos antagonicos, uno de ellos es Mark Strickland en una reciente exposición en el Robert and Francis Fullerton Museum, menciona que: «los seres humanos tienen una dualidad, por un lado son angelicales, y por el otro lado diabolicos, pero

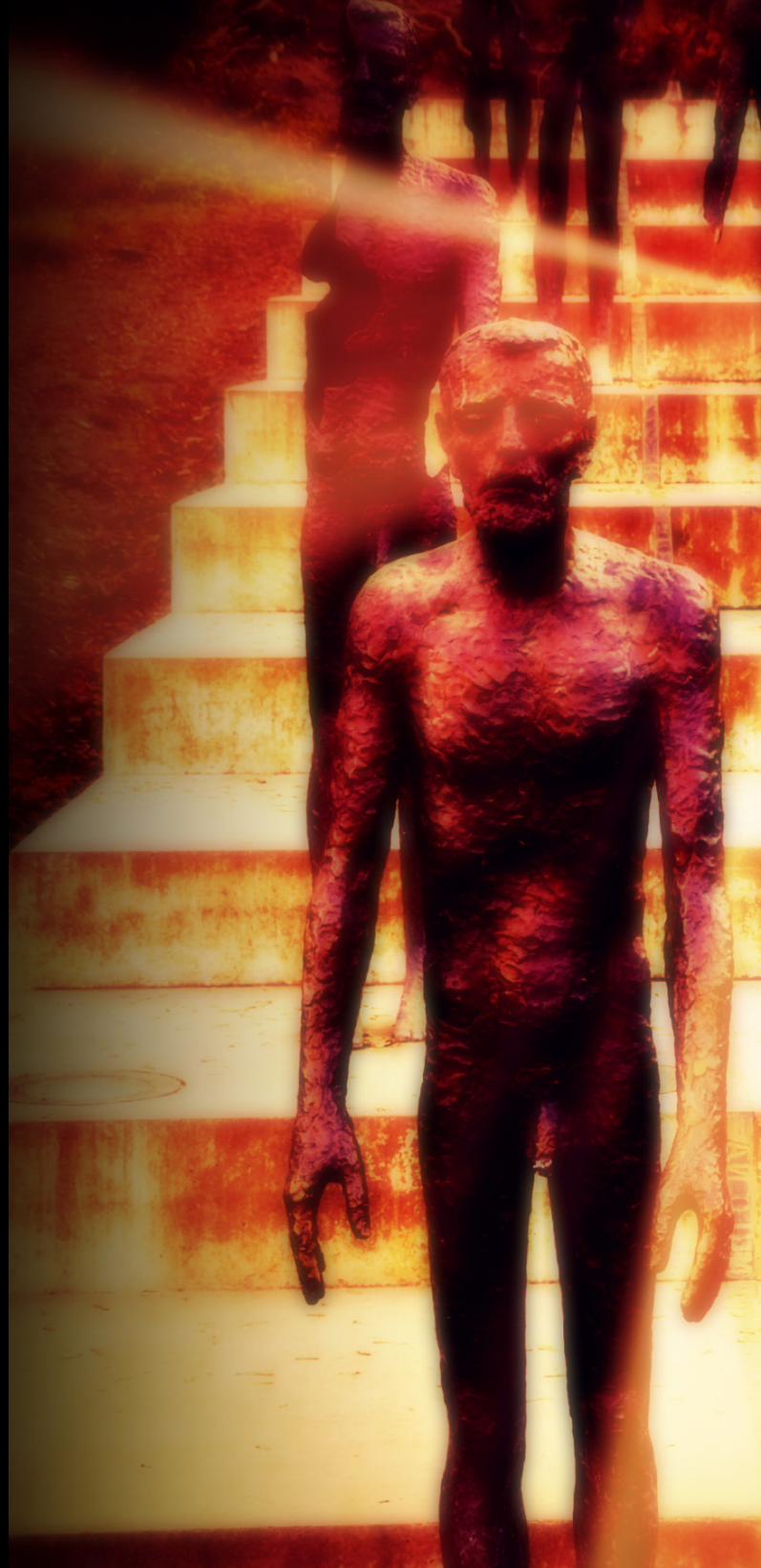

a educación orienta para tomar la decisión " dich frase enfatiza como de alguna forma la educación artistica y el arte como medio comunicativo infier culturalmente en las comunidades y a partir de es te puede existir una narrativa, visual, conceptual emocional que lega a mover las fibras sensoriales de todo ser que aproximandose a una pieza artística o de arquitectura tenga una lectura racional objetiva y real de hechos, en este caso, terribles en el ambito global y permitir sentirse participes de la realidad que si bien es ajena se involucra, se percibe y por que no... por un breve momento llegar a conmoverse. Siguiendo ese concepto figurativo de cuerpo, una preza majestuosa es el ZULO (Figura 5), que consiste en una estatua situada en una plaza publica cerca al ayuntamiento de la municipaldad de Cartagena, Murcia, en Espana, de autoría de maestro Víctor Ochoa, escultor madrileño; la obra de 5 mis de altura 2 toneladas de peso hace honor a las victimas del terrorismo pero también de secuestro y es un recordatorio para todo aquel que la contempla como su autor explico, en «Memoria Dignidad y Justiciam. Dicha obra además inspiro a autor de este articulo a generar 32 piezas visuales de arte digital que retoma la situación de Colombia y el mundo en relación a situaciones deplorables universalmente que merecen ser divulgadas y trasladadas al lenguaje del arte que por supuesto es también un lenguaje universal.

Figura 4. Memorial a las Victimas del Comunismo. Olbram Zoubek (Petrin, Praga).
Fuente: Autor.

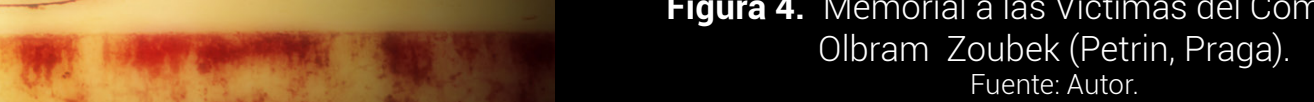




\section{$x^{2}$ (in)}

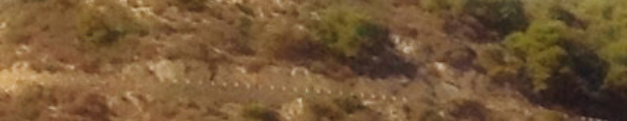

(1)

\section{(-}

$=1$

-

Figura 5. Monumento a las Victimas del Terrofismo

Víctor Ochoa (Cartagena Murcia-España).

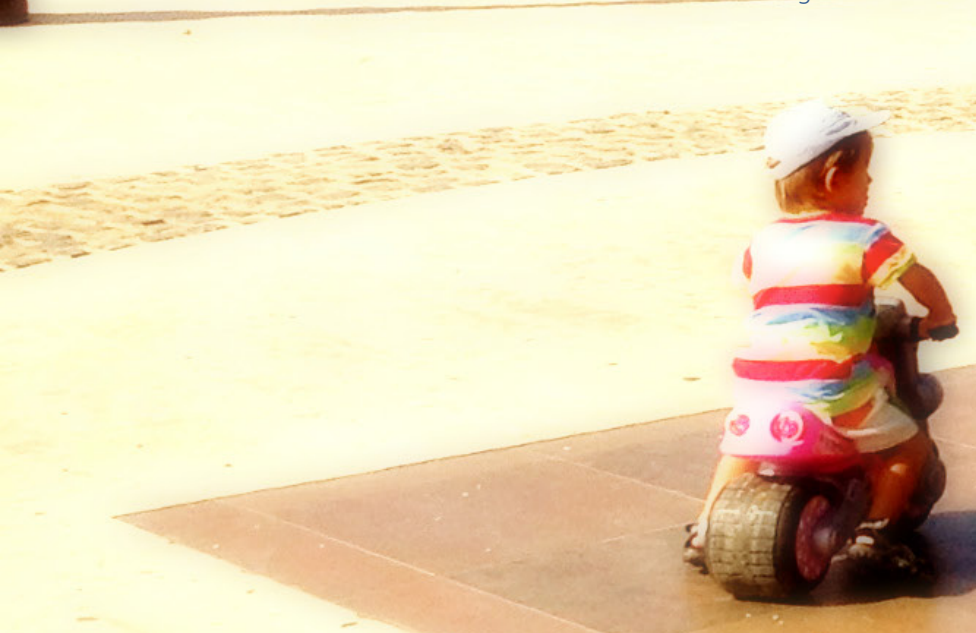

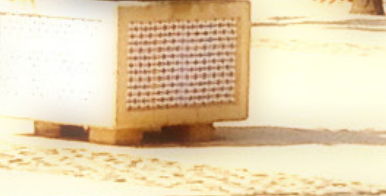

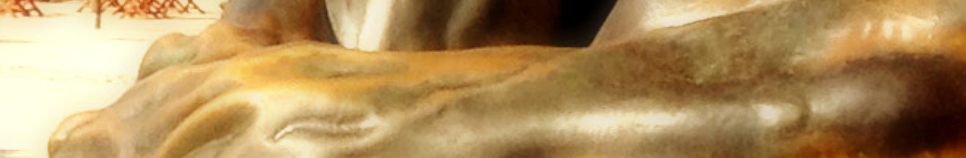

ys: ingesere

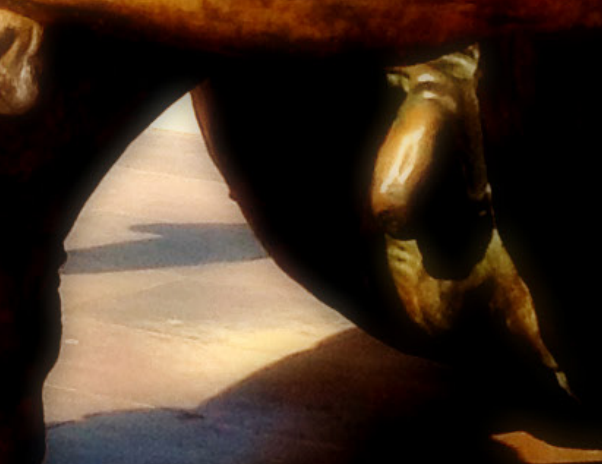
a) 4019 itrs

Un memorial interesante en donde se funde espacio, arte y arquitectura es el Tsitsernakaberd que conmemora al Genocidio Armenio con un anexo a manera de museo de grandes dimensiones, este maravilloso lugar hace honor a las victimas del exterminio del Imperio Otomano entre los años 1915 y 1925 en donde perdieron a vida según varias fuentes 1.5 millones de Armenios. La pagina web: www. genocidioarmedio.org, menciona al detalle las caracteristicas de este monumento en donde todos los 24 de abril se reúnen miles de personas para rendir tributo a los masacrados. La obra fue concluida en 1967, por los arquitectos S. Kalashian y L. Mkrtchian; posee tres cuerpos, el mas emblemático es el muro-mapa de basalto de 100 metros con el nombre de las ciudades y pueblos que fueron arrasados, la piramide fragmentada que es simbolo de las dos Armenias, aquella atribulada y la mas pequeña de las dos porciones que representa la nueva Armenia independiente, la ruptura entre las dos es un signo conceptual a manera de vacio que simboliza a los martires que no se encuentran en la nación armenia y por ultimo e cuerpo central son los doce elementos inclinados a manera de crómlech en piedra basáltica que circunscriben un circulo en cuyo centro se enciende una llama perenne, cada menhir, por así decirlo, representa las 12 provincias en donde la matanza alcanzo niveles mayores. la inclinación es una metáfora de una madre que Ilora por sus hijos asesinados (Figura 6). 


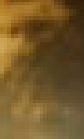
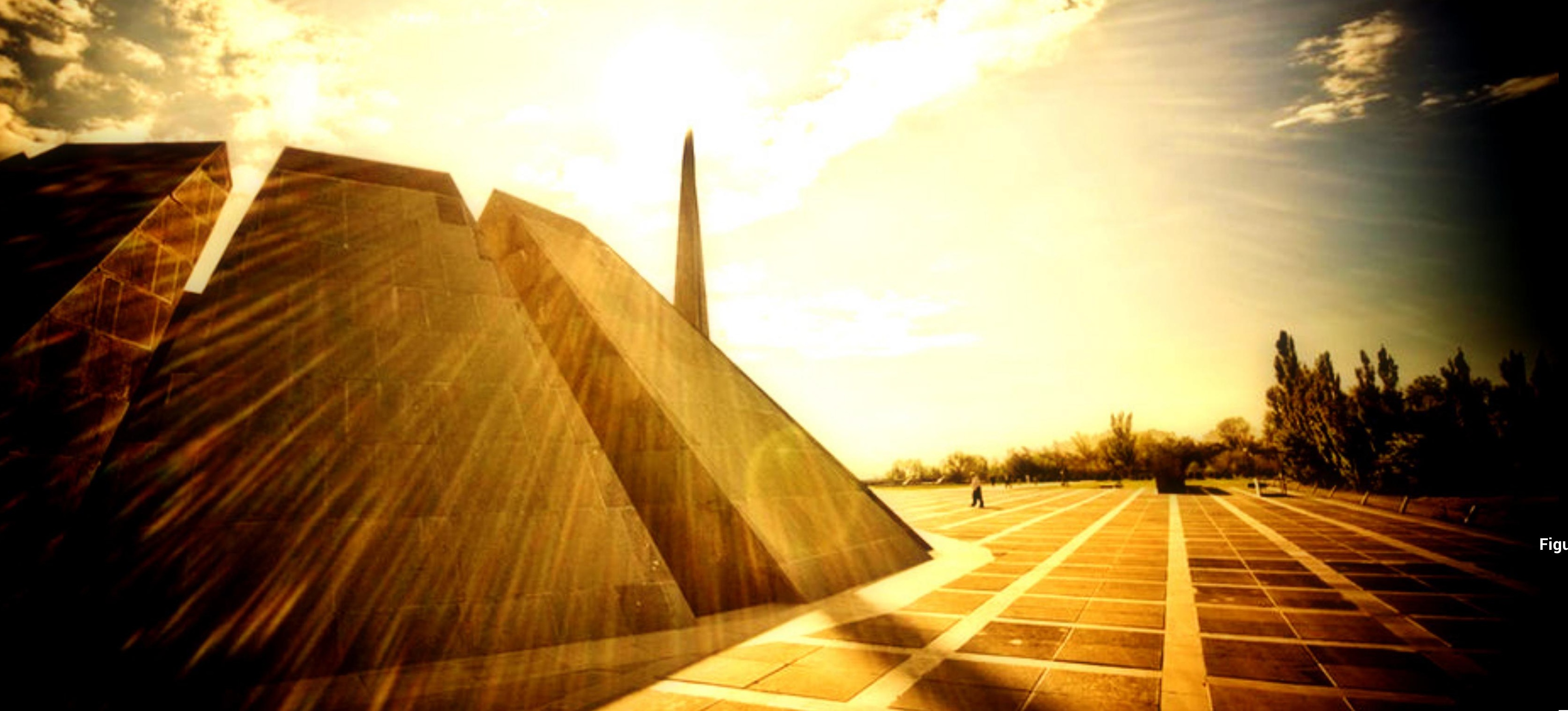

En la ciudad de Padova, en la región Véneta, al norte de Italia el autor vivenció uno de los monumentos memoriales que estando en tierras extranjeras ajenas al acontecimiento terrorifico original es un enclave que determina que el terrorismo no tiene presente fronteras y países específicos en donde se pueda sufrir de este mal del siglo $X X$ y $X X I$ como tampoco tiene limites el sufrimiento de las victimas en cualquier parte del mundo puesto que la perdida el desconsuelo y la fragilidad del ser y del sentir es una emoción compartida que no tiene genero, raza, credo compartida que no tiene genero, raza, credo
o posición socio-cultural. El acontecimiento original se dio en New York, en los atentados del 11 de septiembre a las torres gemelas, un episodio que dividió la historia del mundo en dos partes y que fue y sigue siendo objeto de estudio de análisis, de historias contadas por los sobrevivientes, reportajes, películas de cine dossiers periodísticos que aún hoy después de varios años de este terrible momento para los norteamericanos y para el mundo para los nor año dar. Quizás hoy en día el Memorial llamado 9/11 es uno de los sitios mas visitados del mundo y lugar obligado para todo acus de mundo y lugar obligado para todo aquel que a gran manzana. Construido en el Groun de la gran manzana. Construido en el Ground
Zero el monumento posee varios cuerpos:

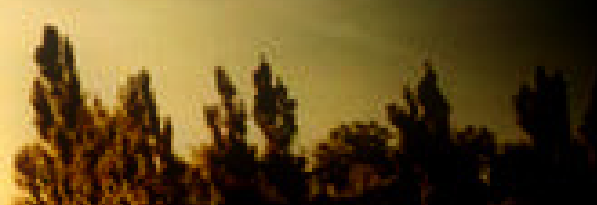
Figura 6. Monumento a las victimas del Genocidio Armenio.
Fuente: www.diarioarmenia. org. ar 
la cascada fuente del norte y del sur que se erigen exactamente en donde estaban los cimientos de los dos rascacielos que fluye sin cesar y envuelve al lugar de un ambiente de respeto y de profundo recogimiento, de alguna forma, al parecer del autor de este articulo es como si las lagrimas de quienes perdieron familiares, amigos y conocidos, estuviesen derramándose por los 4 costados de las fuentes además que sobre ellas hay un bajo muro a manera de plataforma que se convierte en un enorme epitafio donde estas grabados en bronce los nombres de todas las victimas directas e indirectas de los aviones que impactaron los edificios.

La Memorial Plaza es otro de los cuerpos de este monumento nacional estadunidense, con un área de casi 2.5 hectáreas plantadas con 400 arboles, uno de ellos emblemático, un peral que a pesar de ser aplastado y quemado resurgió como un ave fénix y esta lleno de vida por lo cual es el símbolo de la esperanza, en dicha plaza, se encuentra un tercer cuerpo, el Museo Memorial que fue dado por comisión al grupo SNSHETTA y Davis Brody Bon, el concepto en palabras de sus creadores fue:

Según Craig Dykers, responsable de Snøhetta; Nuestro deseo es que los visitantes puedan encontrar un lugar que es un umbral de origen natural entre la vida cotidiana de la ciudad y la calidad única espiritual del Memorial. Es importante que la gente se involucre físicamente con el edificio y sientan que ayuda a llevarlos a otras áreas del lugar y otros pensamientos acerca de sus experiencias allí...
"La transparencia del diseño acristalado promueve una invitación para que los visitantes entran en el museo y aprendan más. Con respecto al Museo subteráneo el arquitecto Davis Brody Bond comenta: "... La esencia de lo que llamamos arquitectura, la gente y las estructuras que construyeron, son la base del National September 11 Memorial Museum..." (Wikiarquitectura, N/S).

De otra parte es interesante como el concepto se apega literalmente al suceso ocurrido de manera contundente así:

La preservación histórica de la zona no sólo era un deseo del arquitecto para el diseño del museo, sino también un requisito legal. Cuando las Torres Gemelas cayeron el lugar se convirtió en una zona histórica protegida. El Museo está, literalmente "construido en un sitio arqueológico contemporáneo", mostrando algunos de los materiales arquitectónicos y de ingeniería dejados atrás, los restos de lo que fue, entre ellos; Algunos cimientos de las Torres Gemelas originales, un muro de contención, conocido como el muro pantalla, dos vigas de acero tridentes de 7 pisos (bifurcadas) de las Torres Gemelas, los restos de la estructura exterior de las torres conocida como "caja de columnas", el acero estructural del punto de impacto, donde el vuelo 11 se estrelló contra la Torre Norte y en nivel más bajo, los visitantes pueden ver un camión de bomberos aplastado por la escalera 3, una pieza de la antena que se había coronado la Torre Norte y la llamada "Última Columna", un elemento de acero de $10.97 \mathrm{~m}$ que fue el último elemento retirado del lugar. También están los restos de 73 columnas base que rodean las dos huellas de las torres perdidas, marcando el ritmo de la estructura de elevación de Minoru Yamasaki quien diseño las torres originales y finalmente la Escalera del Sobreviviente (Wikiarquitectura, N/S). 
Otros dos elementos arquitectónicos están completando este conjunto arquitectónico y escultórico, la Estación del metro, llamada Oculus, del mega arquitecto Santiago Calatrava, amado y odiado por muchos, quien uso la metáfora de una paloma alzando el vuelo, pertinente símbolo de la paz, en un lugar que fue objetivo de una guerra que aun no termina y la Torre de la Libertad, cuyo verdadero nombre es One World Trade Center, el tercer edificio mas alto del mundo, diseñado por Owings \& Merrill Skidmore, David Childs y Daniel Libeskind, este ultimo uno de los mas importantes arquitectos del mundo.
Todo lo anterior recién expuesto, pertenece al episodio original, y consecuentemente al concepto tanto de forma como de contenido, la relevancia internacional de este acto de violencia inconmensurable, pero también de respuesta esperanzadora desde la arquitectura, el urbanismo, el diseño y el arte, toma eco en un lugar a 6648 kilómetros de distancia atravesando el océano. En Padova (Italia), se rinde homenaje a los caídos, con un espacio publico a manera de memorial y para explicarlo se toma directamente de la pagina web de la Red Cívica del Comune de Padova (Padovanet, 2018) algunos apartes de la noticia publicada sobre el Monumento Memorial la cual es traducida con adaptaciones mínimas por el autor:

Nell'area delle Porte Contarine si trova uno dei pochi monumenti contemporanei della città, l-opera Memoria e Luce di Daniel Libeskind, architetto statunitense di origine polacca di fama internazionale, riconosciuto come uno tra i dodici più importanti architetti mondiali e già vincitore del concorso per la ricostruzione dell.area di Ground Zero a New York.Si tratta di un.imponente struttura luminosa realizzata in vetro e acciaio a ricordare le vittime dell-attentato al World Trade Center dell.11 Settembre 2001. Nella zona verde che lambisce via Giotto e si inserisce ai piedi del Ponte di corso del Popolo si è quindi trovata la collocazione ideale per questa struttura che vuole richiamare l.attenzione a valori come la pace, la libertà, la convivenza e l.unione delle culture, utilizzando un linguaggio contemporaneo, anche "urlato", nella verticalità del corpo centrale, e rappresentativo del dubbio, della difficoltà ad affrontare I.incomunicabilità, nell.opacità del vetro, ma anche moderna fiaccola di speranza grazie all.illuminazione interna (Padovanet, 2018)(Figura 7) 

Padova ancora oggi ci insegna che non dobbiamo ave-
re paura della scienza [...] Dobbiamo invece avere paura dellignoranza e dell . intolleranza che sono le cause principall della violenza e del fanalsmo.m. La struttura si comun. altezza variabile de 2 a 5 metri, che termina in un cuneo alto 17 metri, formato anch.esso da due pareti di vetro a forma di libro aperto.All.interno di una di queste due pareti è incastonato il frammento, lungo quasi sei metri, del World Trade Center.Lopera cambia luce e caratteristiche a seconda dell-angolo di osservazione: il punto sra il Piovego Il vetro di cui si compopolo, che attraverè stato appositamente adattato alle specifiche esigenze di questrimportante opera architettonica. Infatti, la luce si fa materia e ridisegna gli spazi e le forme in maniera armonica.La lavorazione ad alto contenuto tecnologico, inoltre, rende il vetro satinato utilizzato vellutato al tatto us significa digent ostera è spiegato chiaramenta dalle parole di Libeskind stesso' L a luce delle Libertà splende attraverso il Libro della Storia. Questo Libro è aperto in memoria degli eroi dell.111 settembre. Leterna affermazione di Liberta e e iscritta nella Statua della Libertä, come e stata vista da milioni di emigranti che arrivavano in Amerc recuperata dall tracco a Wortd Trade Center. La latitudine di New York è connessa al centro di Padora daIla cerniera verticale del Libro. II Libro è luminoso, come il basso ed espressivo muro che crea un luogo intimo per la meditazione. La luminosità di questo «faron sarà modulata in ritmı sottill. II Libro e delicatamente bilanciato tra gli edifici storici di Padova, il ponte, il corso dracqua. II preando un spazio he siscopenta delle moria, di ispirazione e di elevazione Questo luogo speciale brillerà giorno e notte e in tutte le stagioni dell.anno (Figura 10 y Figura 11)

Figura 11

Victimas del 11/9 (Padova, Italia).
Fuente Autor
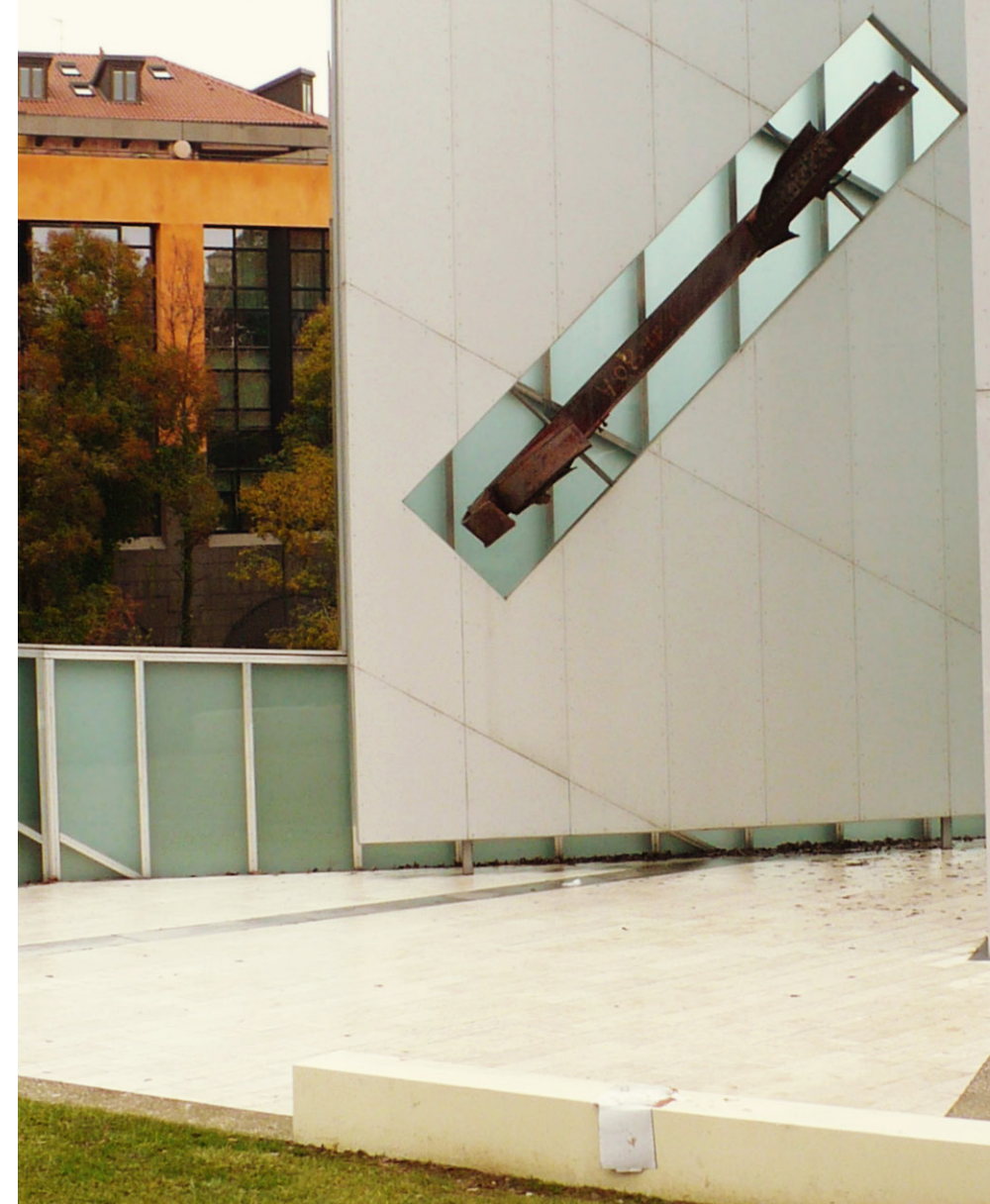

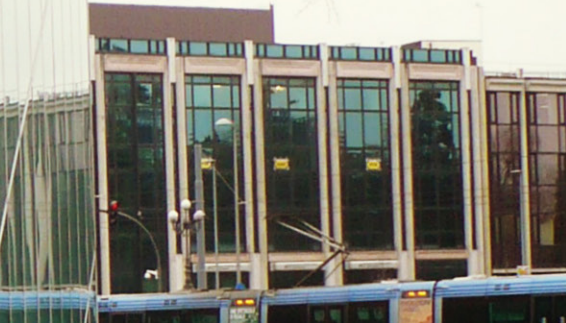

$+1$

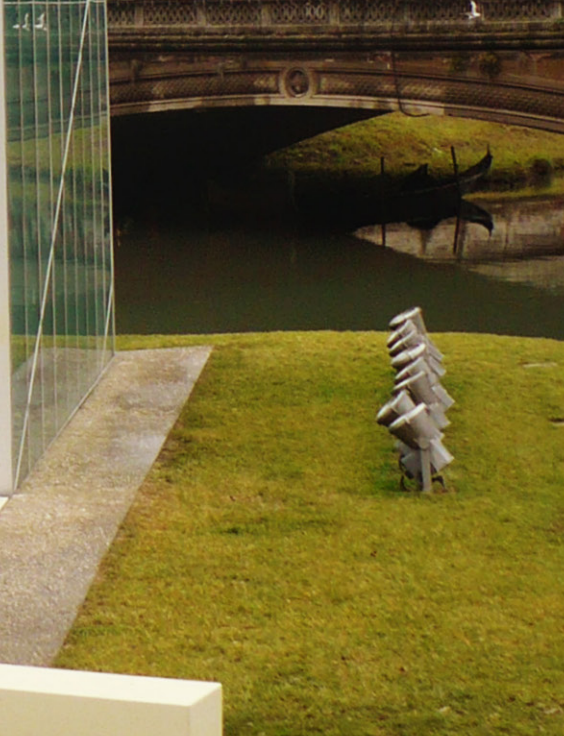




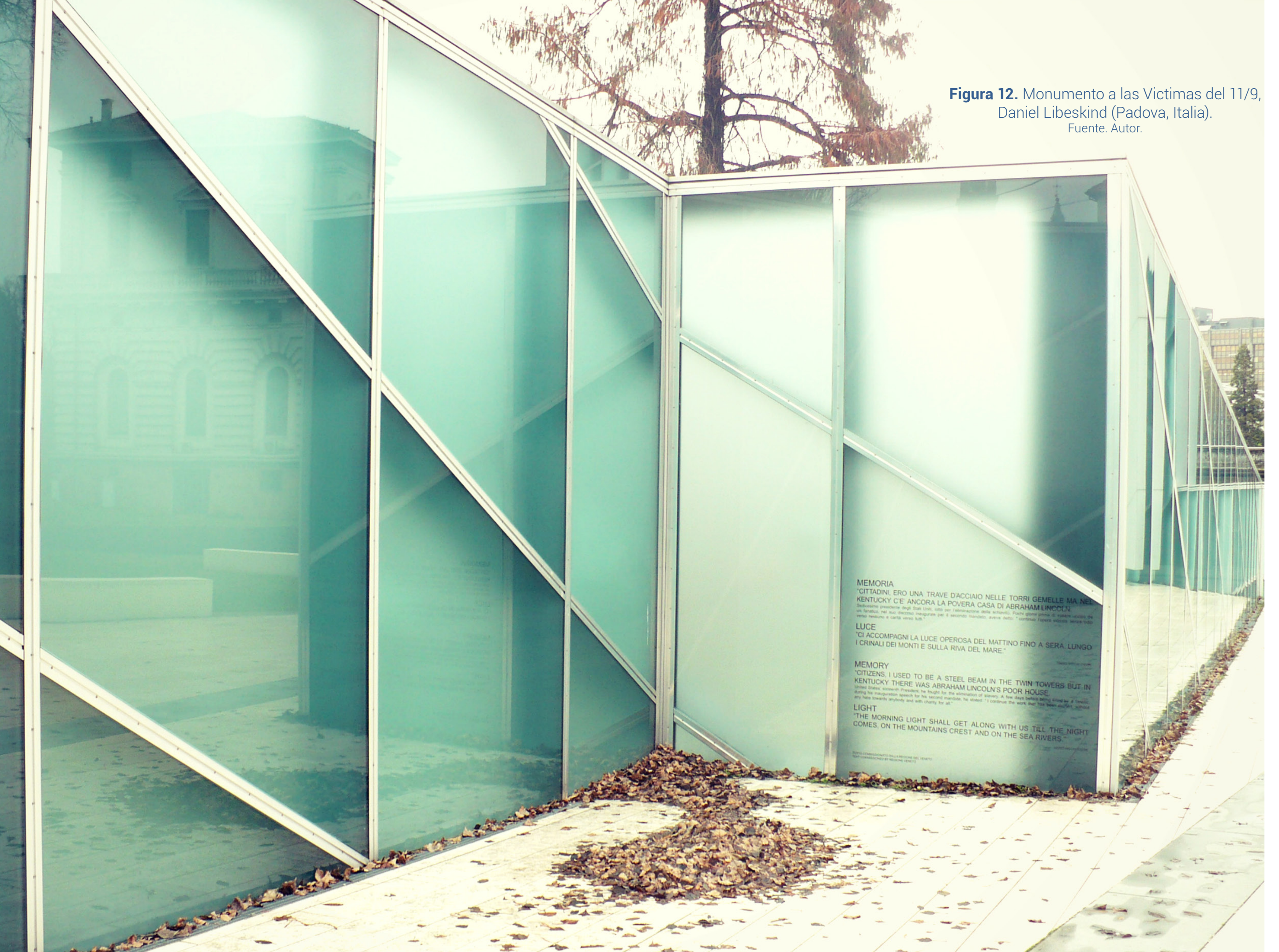

Modul. Arquit. CUC 22(1): 219-286, 2019

Padova, hoy en día todavía enseña que no se debe temer a la ciencia, que por el contrario se debe temer a la ignorancia y a la intolerancia que son las causas principales de la violencia y del fanatismo. La estructura se compone de una pared de vidrio satinado de los 5 metros, terminando en una cuña de 17 mts de alto: formada esta, por dos paredes de vidrio a manera de un libro abierto, en una de estas paredes se encuentra incrustada la viga que tiene casi 6 metros. La obra se caracteriza por cambiar de luz y de forma segun el ángulo de observacion y el punto privilegiado es desde el puente del pueblo que atraviesa el rio del Piovego; el vidrio de toda la estructura fue diseñado apropositio para que se adapte to la luz se hace materia y rediseña los espacios y las formas de manera armónica La elaboración de todo el complejo implico unas tecnologias de avanzada ya que el vidrio se trato para que a tacto, cuando se tocase diese la impresión de palpar una tela de terciopelo además de ser resistente al medio ambiente, incorruptible e inmutable. El significado conceptual de esta obra de artey siguiente retorica: La luz de la libertad se torna esplendor con la el libro de la historia, este libro esta abierto en honor a los héroes del 11 de septiembre, la afirmación eterna de la libertad esta escrita en la famosa estatua de la libertad, tambien en New York, como ha sido vista por los millones de inmigrantes que llegaron a Norteamérica, en este libro, en la pagina izquierda esta inscrita la viga como elemento dramático del ataque terrorista y se hizo titud de la ciudad de New York, con el centro de Padova, desde el lomo vertical del libro, este es luminoso como el bajo y expresivo muro que invita en ese lugar a la meditación y la interiorizacion por la luminosidad de este faro que irradia en ritmos sutiles y ademas permite que el libro se mimetice entre los edificios historicos ve la cludad dellcadamente balanceado entre ellos, el puente, la el patrimonio histórico de las murallas de la ciudad creando un espacio que sea al mismo tiempo un enclave de memoria de inspiración y de elevación, este magnifico monumento brillara día y noche durante todas las estaciones del año (Figura 12). 
La memoria, el tributo y la no repetición: Un Análisis del Monumento Contemporáneo desde la arquitectura y el arte y su Comunicación del Conflicto y la reparación

La arquitectura como toda ciencia tiende a tener su grado de complejidad, a comienzos de la modernidad las propuestas de los arquitectos que lideraron los cambios en la conformación espacial y en el manejo de la forma se rigieron por teorías que si bien respondieron a una postura particular de ver el fenómeno de la creación arquitectónica versus la problemática social del momento, se decanto a los volúmenes pesados, rígidos y cuadriculados del funcionalismo racionalista, soportados sobre los materiales como el concreto armado y el vidrio que fueron los elementos plásticos del momento tanto que saturaron la arquitectura universal estandarizando un criterio de diseño entre lo vertical y lo horizontal hasta que de alguna forma, en contraste, otros arquitectos promulgaron un retorno a lo natural, al equilibrio entre lo invasiva que podría ser la arquitectura y el medio ambiente que la recibía como una intrusa. El Racionalismo, el Funcionalismo y el Organicismo promulgados por los 4 arquitectos que dieron un giro hacia la concepción espacial del objeto arquitectónico y la relación con el cuerpo y la vivencia de este dentro del espacio interior hoy en pleno siglo XXI con los avances en la tecnología y con los nuevos materiales es posible preguntarse si estas teorías son aun factibles o verificables. Estos iconos de la historia de la arquitectura son: Frank Lloyd Wright, Mies Van Der Rohe, Alvar Aalto y por supuesto, Le Corbuiser, ellos sentaron las bases de lo que estaba por venir, después de todo son considerados como los padres de la arquitectura modernista pero la pregunta es i En la arquitectura contemporánea del siglo XXI que se proyecta hacia el futuro, son validos estos principios? lo cierto es que:

Lo monumental es el paradigma de lo actual; A pesar de que los estilos del pasado ya no apuntan hacia otros estilos del futuro, aun por definir, la acción del arquitecto contemporáneos concibe también como un acto artístico en donde se interviene arbitrariamente lo puramente estético, entre una producción y otra, creando por supuesto cualidades formales establecidas por la huella personal que este le imprime a su obra creando así rupturas y desintegrando las formas tradicionales no relacionadas con una continuidad temporal en donde lo monumental es claramente perceptible (De Piccoli, 2011, p. 243)

El concepto de un monumento en memoria de un hecho importante de la vida cotidiana de cualquier comunidad es básicamente servir de medio de comunicación entre el hecho y esa comunidad, en intervalo del hecho, lastimosamente están las victimas y los sobrevivientes que deben ser recordadas permitiendo que a través de la arquitectura y el arte se genere un sistema materico que implique en su diseño y construcción una de las muchas maneras de reparación a esos miles de hombres, mujeres y niños que sucumbieron a un desastre, sea cualquiera que sea, desde un conflicto armado, el alto grado de criminalidad e impunidad, un accidente natural o artificial en donde se perdieron vidas. La arquitectura y el arte por su alto contenido metafórico, sintáctico y metonímico, poseen en si mismas una forma de co- 
municación por códigos entre emisores y receptores, entendiendo como emisor el arquitecto que diseña o el artista que crea una pieza de arte o de arquitectura y el receptor; todo ser humano que esta en contacto directo o indirecto con dicha obra de arquitectura o pieza de arte, ambas soluciones que ayudan a dejar un vestigio que tiene en cuenta la memoria histórica de esa comunidad o nación, que por medio de signos y significantes, muchos de ellos de carácter simbólico permiten establecer un medio de recordación, de reparación y de conciencia social que colaboran en la mejor manera posible al enviar un mensaje, y este es: la no repetición y exaltación, como se a ilustrado hasta el momento.

Son muchos los flagelos que atentan contra la dignidad humana y también son muchos los esfuerzos de las diferentes sociedades a nivel mundial que buscan dejar un legado a las generaciones por venir para que no ignoren los sacrificios de sus antecesores, por tal motivo, La arquitectura y el arte y el diseño por supuesto utilizan estos entes arquitectónicos y artísticos implantados es espacios públicos para promover el recuerdo del hecho y culturizar a una determinada población para que siendo conocedores de la dolorosa realidad de las victimas éstas, sean un motivo de inspiración y de respecto, por lo tanto iconos de la victoria a pesar de lo espantosos que pudieron ser tales hechos atroces que mancillaron su propia identidad, aportando, desde estas disciplinas plásticas un sendero que lleve a la verdad, un sitio de reunión para reflexionar y al final de todo un tratado visual que involucre el deseo de estar en paz y de que ésta sea duradera. Dicho esto, así como se escogieron 7 episodios deplorables y caóticos en la historia del ser humano con sus connotaciones de violaciones a los derechos humanos, al derecho natural adquirido de estar en paz, y a la socavación de todos los principios éticos y morales establecidos por una sociedad contemporánea que dice estar amparada por la ley y la justicia en el orden universal de convivencia entre comunidades,pueblos y naciones, se seleccionaron a criterio del autor 7 arquitecturas monumentales que son la recordación de algunos de esos hechos y que invitan a la reflexión sobre nuestra naturaleza humana. Por otra parte, este articulo fue en su momento ponencia y caso de estudio ante un grupo de 60 estudiantes de taller 2, y los docentes integrados. Arquitectas: Eneyda Abreu Plata, Irasema Venegas Ahumada y Yolanda Pinzón como metodología en la visión de la Universidad Santo Tomas, del ver, juzgar y actuar y ejercicio de diseño de final de curso en el 2019-01.

Estas piezas de arquitectura y de arte, son comunicadoras silenciosas de hechos que en su materialidad, concepto de diseño y su claro objetivo de ser un voz que pretende llevar cosmos y equilibrio al caos y el conflicto en el cual se habita actualmente, son una pequeña porción de los miles de elementos conmemorativos erigidos para recordar en muchos lugares del mundo a las victimas de un episodio trágico que ciertamente no tienen líneas fronterizas demarcadas. Esta obras y sus creadores dan respuesta a como la arquitectura es mas que materia, es un vinculo artificial creado para transmitir emociones y sensaciones con el usuario, sea este el mas humilde o aquel de mas alta alcurnia, puesto que maneja un mensaje universal cuya comprensión es inmediata puesto que los códigos empleados, en este caso, en 
los memoriales, es dejar un sentido de proximidad entre las victimas y la persona que las contempla a través del espacio diseñado para tal fin. El autor considera que entre muchas de la sensaciones sentidas en estos sitios de de la sen raciordación el respeto y la admiración hacia los caídos debe ser superior a la lastima y la tristeza.

El primer ejemplo seleccionado es el Memorial a Sean Collier en el MIT, ideado po Howelert-Yoon Architecture (Figura 13 y Figura 14), en honor a un miembro de la policía loca debido a que el 18 de abril de 2013 fue asesinado 3 días después del atentado terrorista la carrera la Maratón de Boston, el monumento es una sinfonía de metáforas que traducen en piedra el acontecimiento del magnicidio, se trata de un concepto que si bien es singular podría verse como representación de un hecho de carácter internacional como homenaje todos los agentes del orden publico que velan por la seguridad de los ciudadanos en todo el mundo La pieza es una estructura orgánica ondulada y sinuosa que maneja dos conceptos fundamentales: Fuerza y Unidad la unidad hace la fuerza un valor muy arraigado en comunidad Norteamericana y en ese lema de co dejar a nadie nunca atrás, como bien reza el dicho, la materialidad es el granito a manera le bloques que dan origen a una bóveda cuya metáfora es una mano que se abre y sus demetáfra es una moro 5 dirciones; esta sus deneos apuntan 5 direciones, esta acompaFigura 14. Monumento a Sean Collier en el MIT, Howelert-Yoon Architecture (Boston, USA)
Fuente: www.metalocus.es

ñada de varias leyendas alusivas a la persona- 


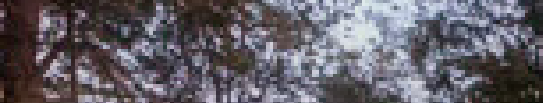

$+5(1)=0$

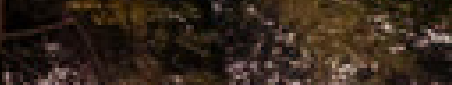

que traduce la memoria convertida en espacio, en un macas a caminable, abierto, experiencial, que transforpresencias permanentes en el espacio y en el tiempo Es de esta manera que Julio Gaeta y Luby Springall autores de la obra arquitectónica, describen al proyecto resultante de un concurso nacional abierto, ubicado en el parque más importantes de la ciudad, el Bosque de Chapultepec. La acción del concurso nacional disparó. por un lado, la recuperacion y creacion de un espacio construcción de un espacio-memoxial. En porbos casos, la condición que domina es lo abierto. Es un proabierto e inacabado: abierto a la ciudad y abierto a la apropiación ciudadana. Como describe Kristin Feireiss, curadora de arquitectura y jurado del Premio Pritzker el Mepta un anfocue hoĺstico qu Vexpesa un Mexico. adoptanitario fuerte presencia física, sensibilidad artística extraordinaria y dialogo poetico con el universo y la naturaleza. Explica que a partir del concepto y diseño del memorial, una instalación de setenta enormes muros de acero y espejos de agua integrados habilimente al paisaje, se han creado formas y espacios que intecon la comunidad. Esta dimensión colectiva la considera como un valor único, ya que crea un espacio en el que todos pueden estar juntos: un lugar para todas las generaciones y nacionalidades, para recordar, conversar y cuestionar -aun cuando no haya ninguna respuesta. Para Feireiss, el proyecto es un gran ejemplo los mem serales a nivel mundial man dar paso al preta memorial, caracterizado por el cambio de monumentos únicos de gran escala a esculturas que se confunden con el ambiente urbano o natural (Proyectobaq, 2017). 


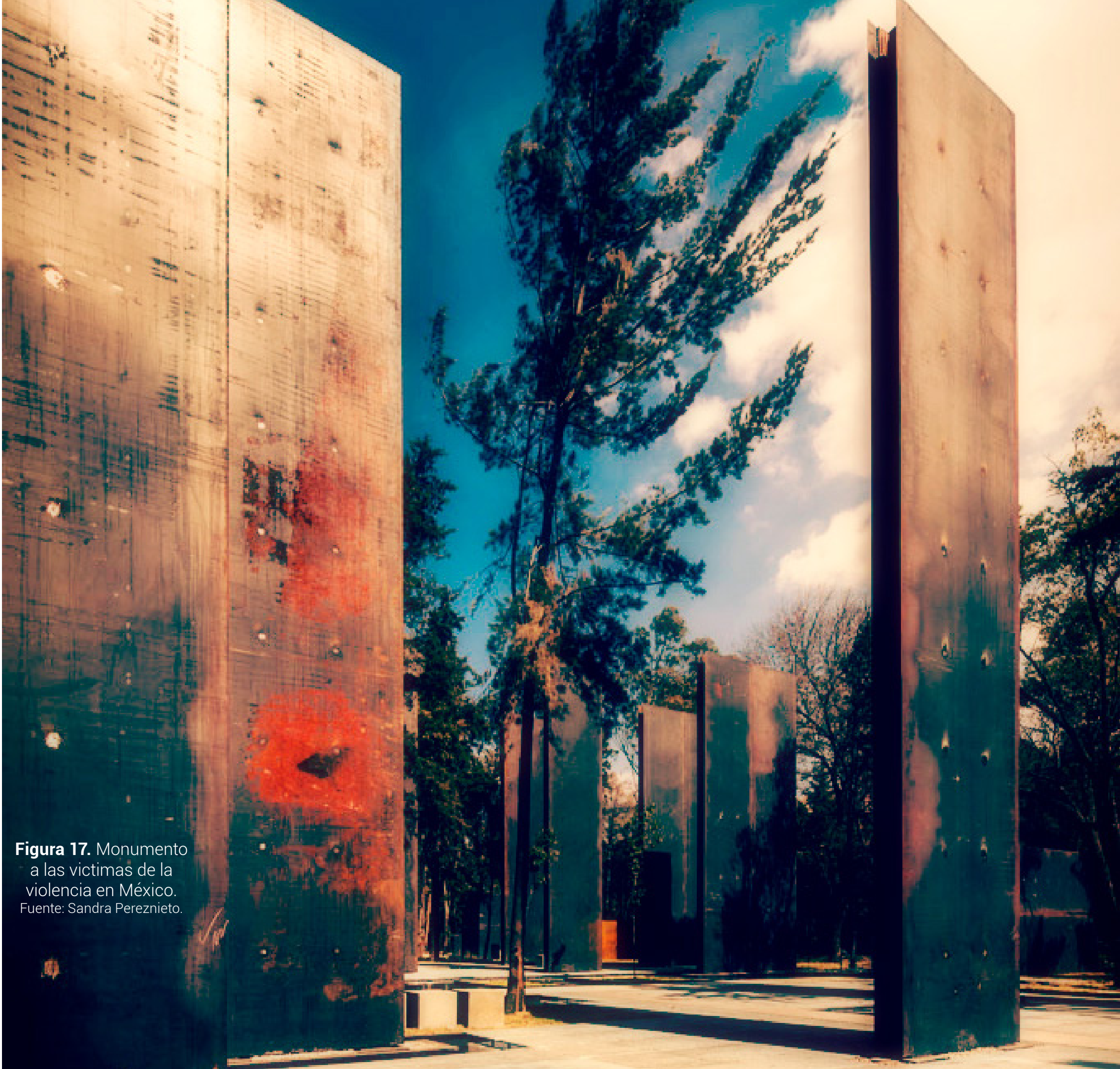




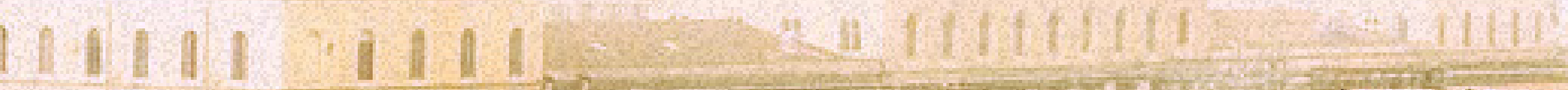

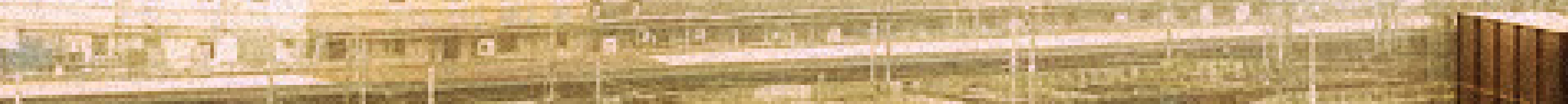

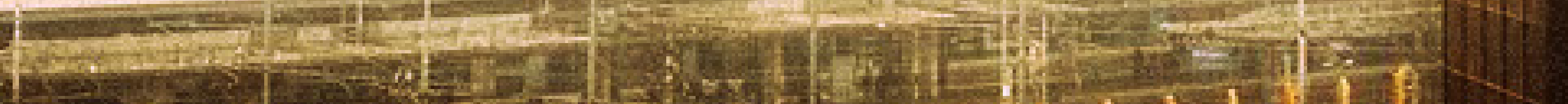

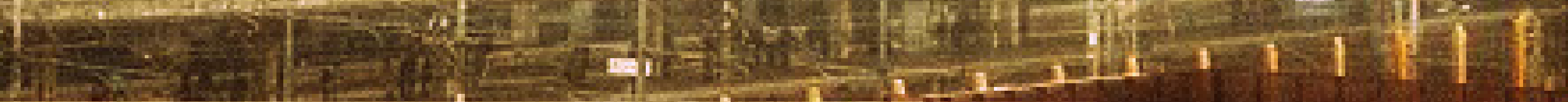
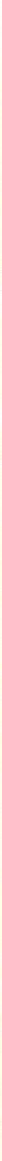


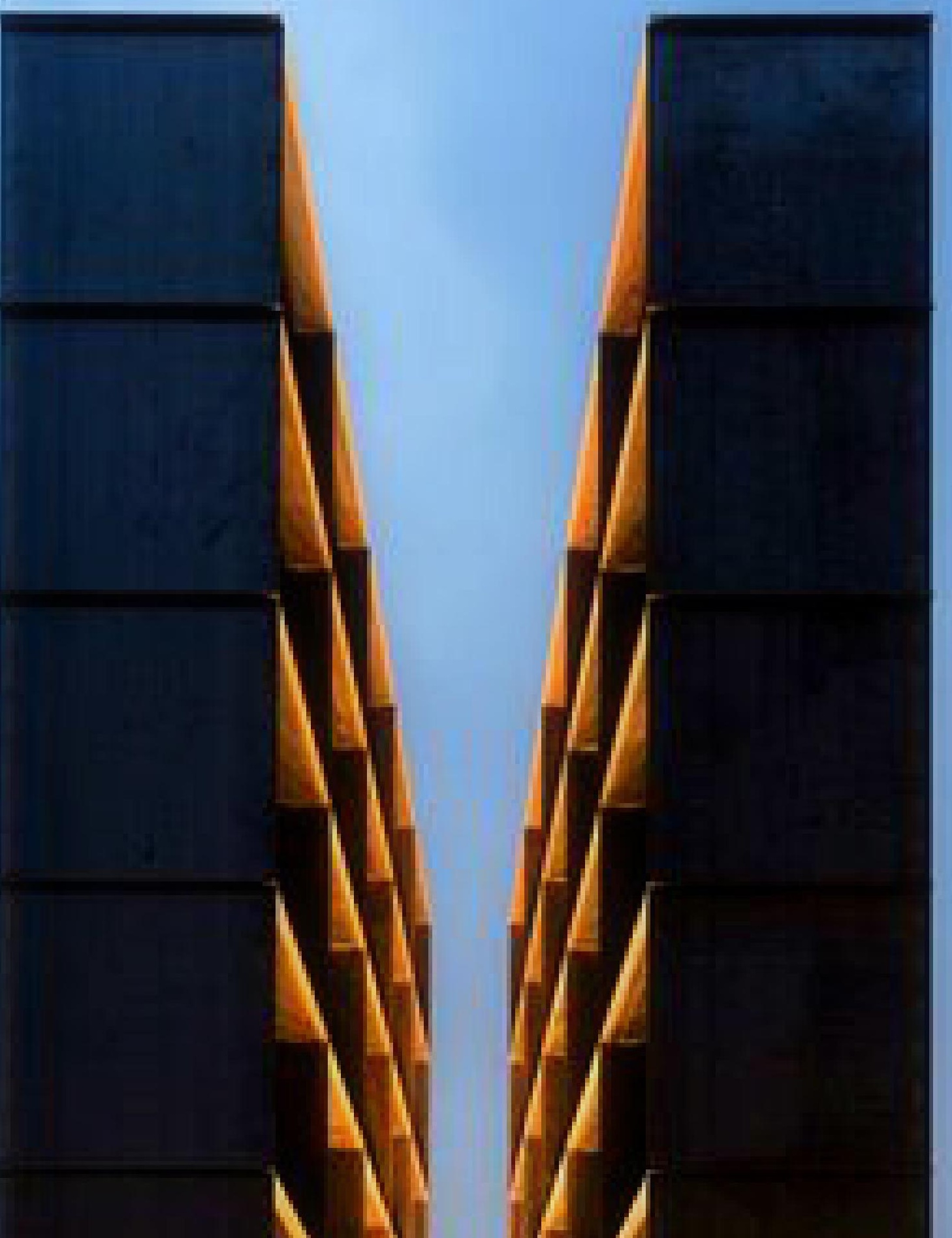

No se puede negar que la arquitectura, la

buena arquitectura y el buen diseño debe estar inmersa en los sentidos y en las emociones, ya que no se trata de un conjunto de materiales dispuestos y organizados con un grado significativo de composición y coherencia, la arquitectura va mas allá, es una expresión de un momento determinado en la historia del hombre una respuesta a una situación problema y fenomenológica que en el mejor de los casos podrá permanecer mas tiempo de quien aquel que la diseño y la construyó dejando así un vestigio de su propia creatividad y del mensaje que en su momento quiso transmitir. Por algo al final del camino muchos de estos edificios emblemáticos se convierten en patrimonio, una memoria que debe esta ligada si o si al desarrollo cultural de un pueblo y que mas importante que la memoria de los hechos fatídicos puesto que son esos avisos silenciosos que sin embargo gritan a voz viva lo que como pueblo o nación no se debe olvidar para no repartir situaciones aberrantes que lastimosamente si no hay una voz de reclamo o de denuncio tarde que temprano ese hecho se repetirá y quizás con ecos que terminen por aniquilar y quizás con o nación que no escucho su propio legado histórico condenándolo al olvido.

El cuarto memorial seleccionado es: Nuovo (Figura 20, Figura 21, Figura 22) que cor simbólico para la ciudad de gran fuerza física y que se correlaciona con la fuerza emocional 


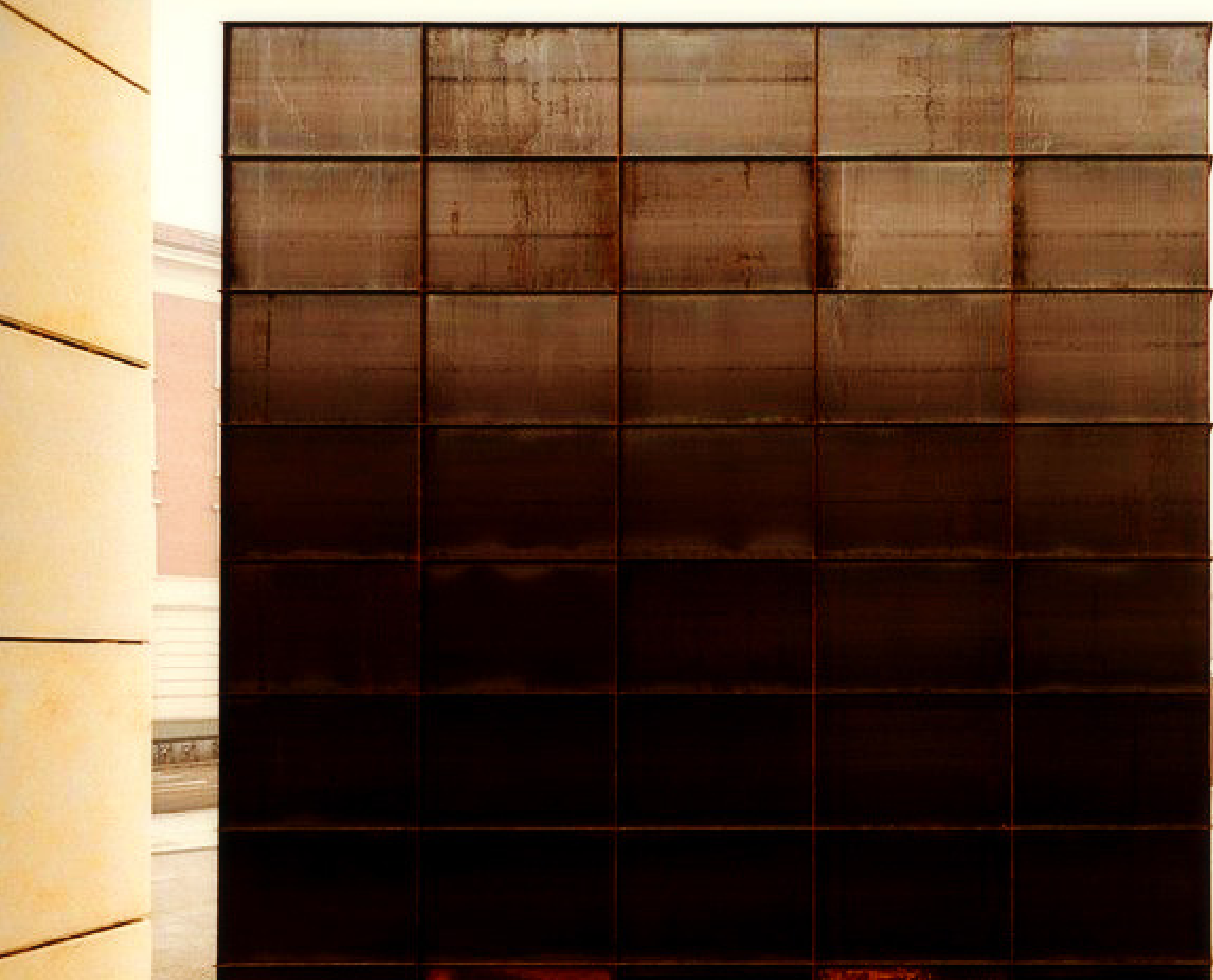

Figura 21. Monumento a las victimas del Holocausto (Bologna-Italia).
Fuente: Simone Bossi.

ins

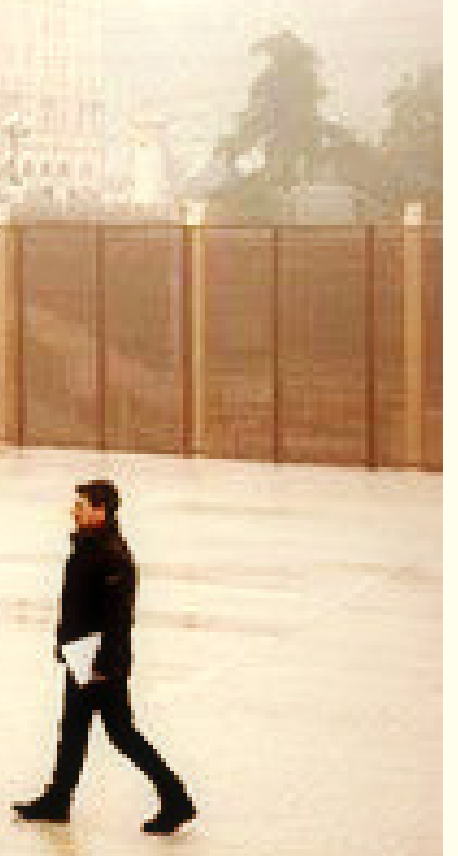

que este transmite, como bien se ha visto en este proceso de investigación sobre la arquitectura conmemorativa la cual está marcando un hito material en relación al tributo y a la memoria no se requeriré realizar algo de dimensiones mayúsculas para no crear ese impacto visual que se busca en esta tipología arquitectónica monumento esta localizado en la intersección de la Vía de Carracci y el Ponte Matteotti, cerca a la estación de trenes por lo tanto es una plaza publica en si misma que propende a sr punto de pasaje, de reunión y de transferencias a muchos puntos de la ciudady que por su propia envergadura no es tan pequeña en términos de metros cuadrados si se le compara con el Monumento de Memoria e luce en Padova pero cumple con el mismo objetivo sentar un precedente materico arquitectónico y artístico de gran contraste en el entorno que invita al transeúnte a llegar instalarse recorrerlo y por que no meditar sobre la situación que lo llevo a pasar de ser de una idea de tributo a un lugar de permanecía y memoria individual y colectiva. La palabra SHOAH d

(lenguaje Hebreo sigesta, Catástrofe, y fue la comunidad judía de sín ralepínedos simétricos de acero no inoxidable de $10 \times 10$ ms cala uno los dos elementos geométricos y densos se disponen uno junto geometricos y deacos uno; los dos elementos sendero que cambia su ancho de $1,60 \mathrm{~m}$, estresendero que cambias ancho de 1,60 m, estre- 
se unen en ángulo recto de $90^{\circ}$, originando unas

celdas vacias rectangulares de $1,80 \times 1,25 \mathrm{~m}$ - el

contenido simbólico de estas oquedades es la

representación metafórica de las habitaciones de

dormir en los campos de concentración el acero

no oxidable es un material que se corroe se le

conoce como acero dulce o acero al carbono

cuando se expone al aire libre se va degradando

asílas piezas en el pasar del tiempo evidenciaran

la patina del oxido, Los elementos, todos en su

conjunto crea un ambiente de respecto y de

dimensionesmelodramáticas dondenuevamente

la luz juega un papel importante en los ritmos

del memorial, con luz natural, el corredor entre

los bloques se disloca en en una luz casi

imperceptible dando claroscuros a recorrido, la

luz artificial ubicada en puntos estraténicamente

seleccionados permite que el recinto adquiera

una presencia imponente, poderosa y al mismo

tiempo inmaculada donde lo majestuoso se

hace metaly concreto en donde se evidencia lo

inconmen y coble de holocausto la desmedida

modo destructivo y lo que queda después de la

destruccín fragmentos, estos dos fraencentos

son un testimonio metafórico de esos hechos

que lastimosanionte siguen aconteciendo en

que lastimosamente contemporánea.

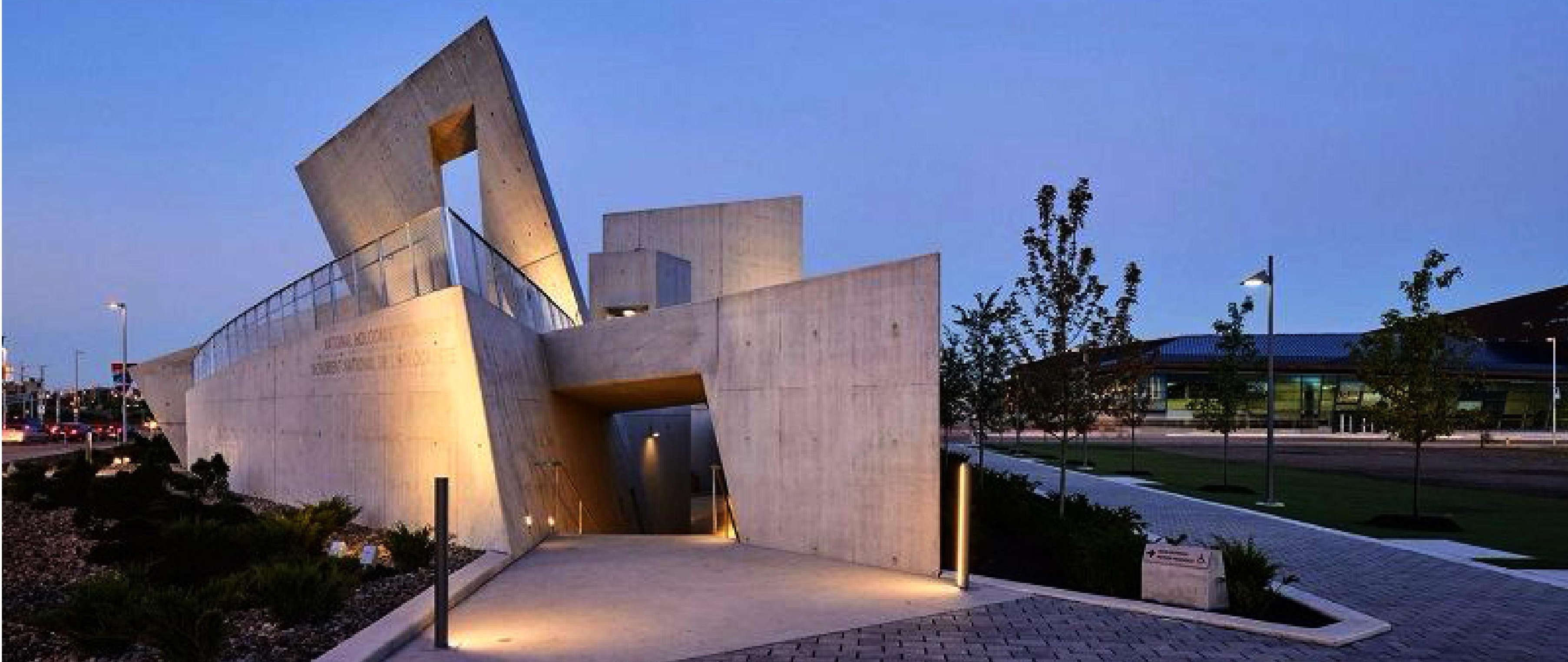



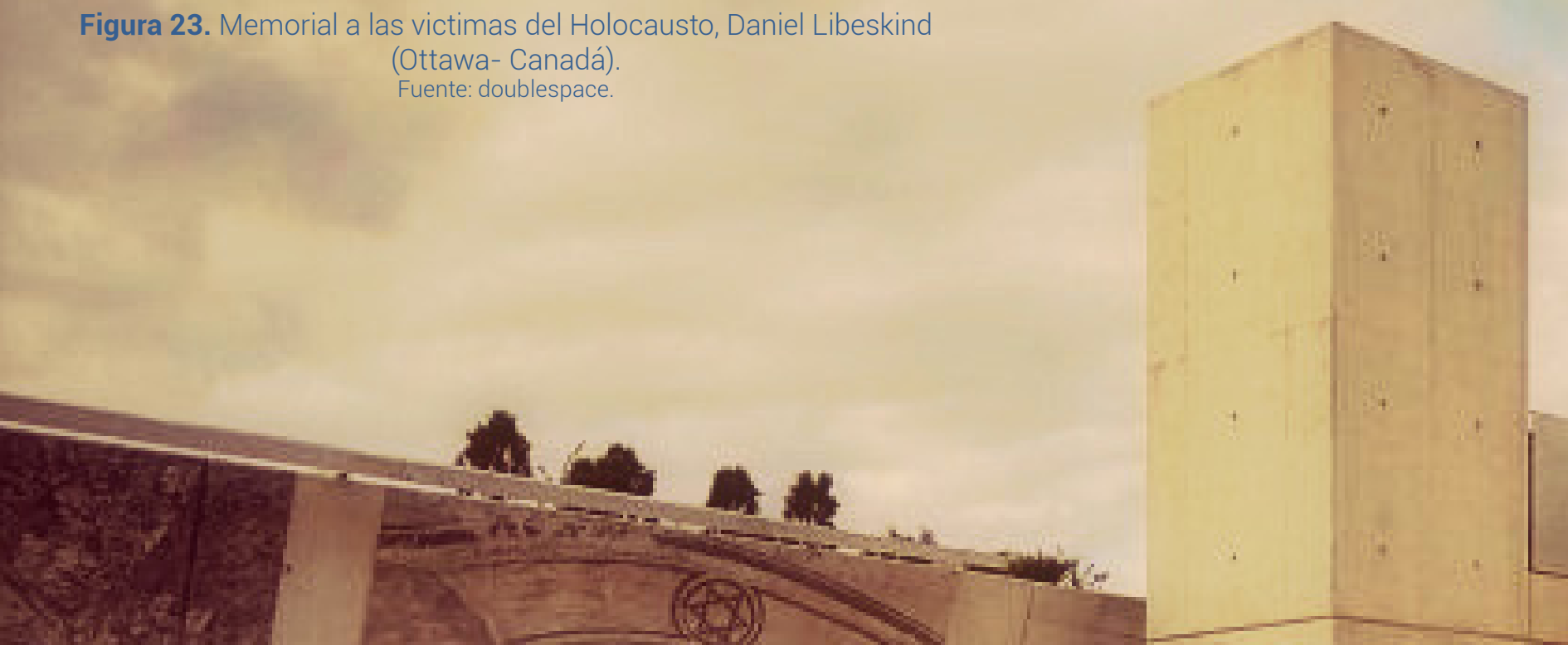

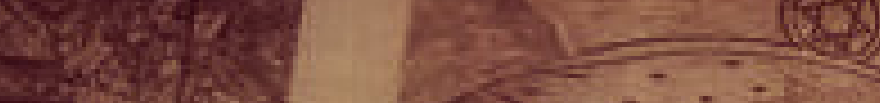
Wh. sisy ghe Whe (1) b b ( .
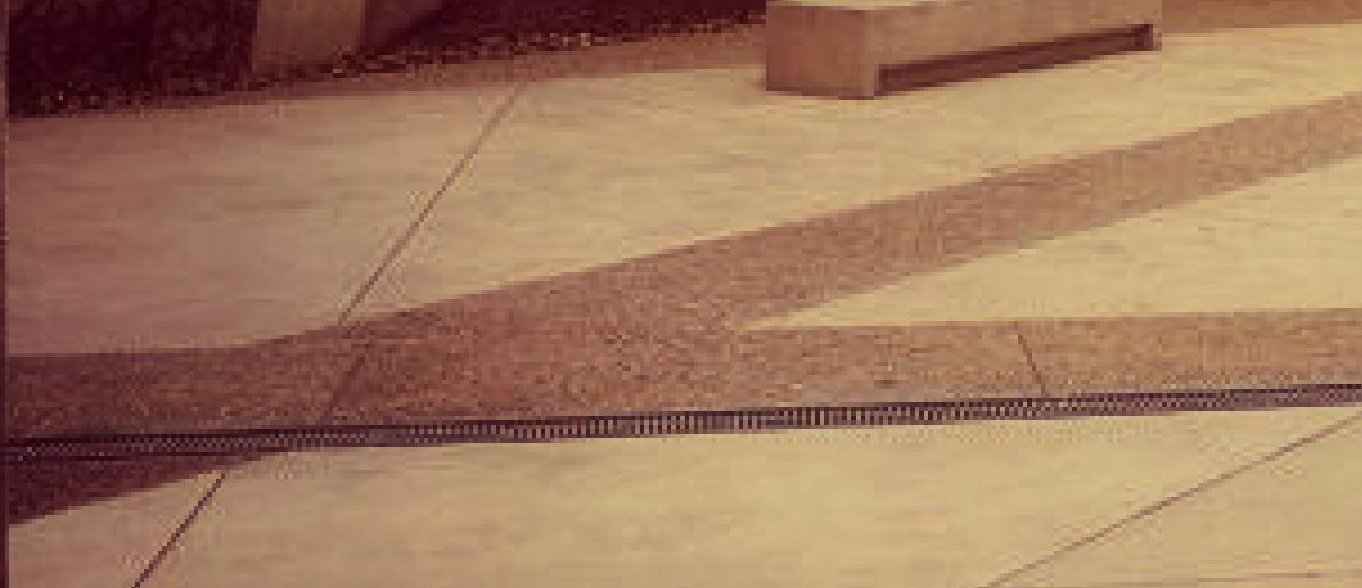
ARQUITECTURA: MENORIA Y TRIBUTO.
ESPACIOS DESTINADOS AL RECUERDD, LA VERDAD Y A LA NO REPETICIÓN DE LA BARBARIE HUMANA EN TIEMPOS DE PAZ

Libenskind se basa en la forma de una estrella de David, una estrella de seis puntas símbolo del judaísmo y que ha devenido símbolo de las víctimas del Holocausto, al ser, precisamente, una estrella amarilla conformada mediante dos tríngulos equiláteros la en consecuencia se forma a partir de seis volúmenes triangulares realizados en hormigón in situ. La forma estrellada que se consigue se adapta a la parcela mostrando un carácter irregular, casi deformado, de muros inclinados, pasos estrechos y pasajes laberinticos, reflejo del dolor y el sufrimiento. Los espacios triangulares resultantes recuerdan, igualmente, religiosos, testigos de Jehová, homosexuales, gitanos y otros individuos de razas y etnias diversas. E espacio, fragmentado en ámbitos estrechos, alargados, de formas agudas, de salientes y aristas vivas, se convierte en un espacio herido, rasgado. Los muros, que delinean estigmas y cicatrices tridimensionales, leza no tiene cabida. El gris absoluto del hormigón ha engullido todos los colores, y sólo el azul sobrevive en lo alto, en el cielo. El interior, acotado por los muros, apenas permite la conexión con el espacio exterior En su lugar, en determinados puntos se evocan paisajes monocromáticos que, traspasando la dimensión locausto, a los campos de exterminio a los paisajes de muerte y ejecución, Que toda esta arquitectura para el recuerdo nos permita conservar todo aquello que no se debe de olvidar.

En el articulo: Arquitectura, Psicología, Espacio e Edividuo, escrito por Franco (2009), doctor en ciencias humanas en el resumen establece desde ya sin ser arquitecto, el bien ser de la profesión de la siguiente manera:
Modul. Arquit. CUC 22(1): 219-286, 2019

Es necesario la necesidad de conciliar las visiones que se tienen sobre las personas cuando las sometemos bajo un escrutinio artistico (arquitectonico, cenestésico, estético) psicologico (emociones, sentimientos, personalidad) sociológico (cultura, normas, valores) puede caer en el error de pensar en la existencias de verdades y miradas absolutas ni tampoco en las explicaciones provenientes de feudos científicos con barreras y limites infranqueables. Una visión Transdisciplinar se hace necesaria, por cuanto ello permite ver el mismo objeto de estudio desde distintas perspectivas dad" (p. 12).

Sin duda alguna en todas estas propuestas y en terminos generales en la arquitectura contemporáyue las escuelas de arquitectura están adoptando desde hace mas de una docena de años en sus practicas acad́micas para formar profesionas muchmas holísticos, sisténicos y dilógicos. Entender la mas holsticos, sistén foos y dilogicos. En mucher la dando universalmente imp licacion

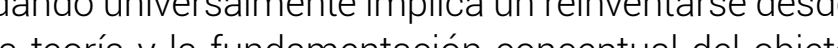

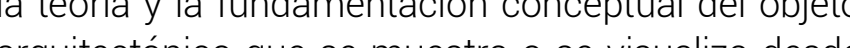
las diferentes visiones de los a squitectos contemporáneos. la vocion de la cenestesia que inplica poraneos la nocion de la cenestesia que inplica lo sensorial delcuerpoy com los reseptores del mismo pa neuronal físico de como percibe el cuerpo desde pa neurer respondiendo a los estmulos que gesde su injer respondíndo a los estimulos que genera que quizás nu eran ton expresivas en la a visuales que quizás no eran tan expresivas en la arquilectura modernista, en la actualidad se tiene muy en ouenta 
ARQUTECCTURA: MEMORIA Y YRIBUTO,
ESPACIIOS DESTINADOS ALL RECUERDO, LA VERDAD Y A LA NO REPETIIION DE LA BARBAII HUMANA EN TIEMPOS DE PAZ

manifiesto físico de pautas formales que pueden dislocar el espacio y sentir la fragmentación, pueelementos táctiles que envían señales percibidas por el tacto proporcionado una gran ideación del cuerpo en relacion al lugar ni hablar de los estimulos visuales a traves del color o la ausencia del mismo, el manejo de las geometrías no platónicas que se alejan de lo tradicional y acercan a la vivencia de espacios disruptivos, translucidos, etéreos, teatrales entre la luz, la sombra y el claro obscuro.
Estos memoriales buscan eso precisamente, establecer esas sanciones para que sean captadas por el usuario y no solo de manera física sino también el proceso mental y cognitivo que racionaliza un símbolo compuesto de signos que por medio de metáfora metonimia y la analogí como nuevos valores sintácticos y semánticos en el discurso arquitectónico que exploran la creatividad para desarrollar estrategias de diseño que llevan en cierto modo a respuestas arquitectónicas con un alto componente artístico de manera inusual.
En este sexto y séptimo referente esa capacidad de integrar por medio de un sistema abierto dentro de un programa de necesidades especificas y además involucrar el dialogo simbólico a base de signos, significados y significantes en doble vía se evidencia e grado de comunicación entre el hecho, la narrativa, la memoria y su materialización como objeto vivencial y emocional. Para cerrar este análisis breve del memorial como objeto arquitectónico no se podría mejar de lado la problemática de la paz en Colombia y para tal efecto se recupero y fue editado y adaptado por el autor en sus determinantes claves de una publicavista digital Plataforma arquitectura, cuyo texto original fue traducido por Cristian Agular, el 25 215 con el Centro de Memoria, Paz y (Figura 25, Figura 26, Figura 27).

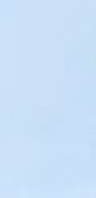




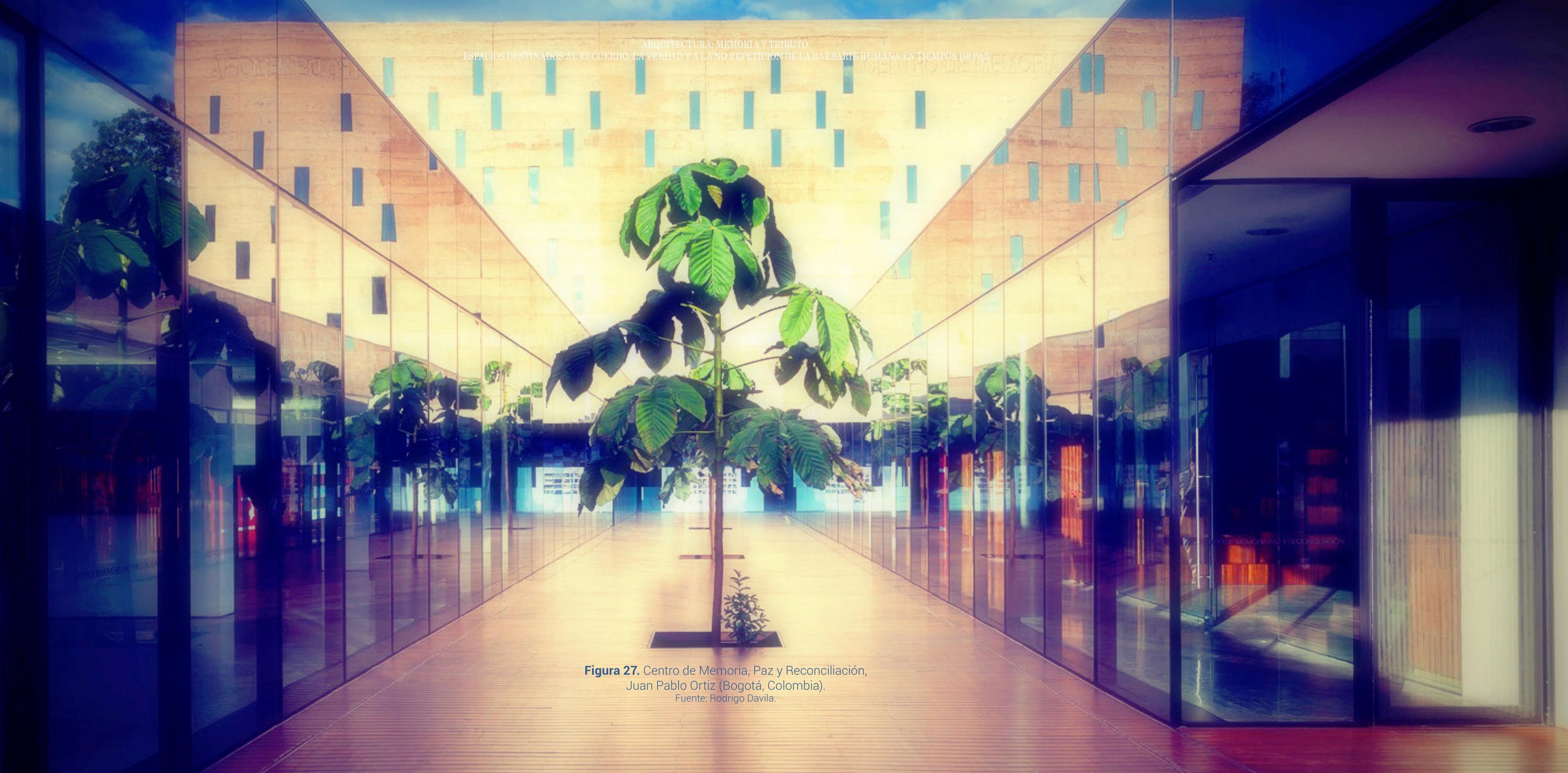


El inmueble se encuentra en la ciudad de Bogotá y su intención es rendir homenaje a las mas de 6 millones victimas directas e indirectas del conflicto armado con la guerrillas de las FARC, el ELN y las Autodefensas y se fundió con la conmemoración de de a la negativa de la violencia, la Justicia y la verdad, aunada a la reconciliación. De manera un tanto paradójica, este monumento a la vida en paz, surge de un terreno de muerte pues el predio hacia parte de un cementerio lo que implico la exhumación de 3600 cuerpos ahí enterrados y siguiendo con la analogía de lo sepultado, el edificio esta debajo del nivel del emplazamiento por lo que quien lo visita debe descender para sentir corporalmente un cambio de dimensión espacial y conectarse con una atmosfera de tranquilidad, reposo, silencio... el estado de la eternidad del alma. Ya que el edificio esta bajo tierra permite además llegar a un lugar solemne donde se hace sensible la relación del visitante con las victimas anónimas que el monumento esta representado y en relación al método constructivo, la publicación original hace la siguiente mención:
Sobre como un método constructivo en tapia pisada tradicional puede utilizarse de manera contemporánea y sirve adecuadamente para fines culturales dandole un sentido al edificio con estos muros de 12 metros de altura, que se construyeron con un metodo que tenia dos sentidos simbolicos, el primero evidenciar que la tenencia de la tierra es el origen del conficto Colombiano, de alli que sistemas ancestrales de construcción en tierra $Y$ e l segundo es una acción simbólica para conmemorar los 200 años del Bicentenario; que consiste en la construcción de este volumen monolitico con una estratigrafía marcada por 20 capas vaciadas en anillos, cada uno de estas corresponde a una década de nuestra historia republicana. El proyecto propone ir mas alla de las cualidades inmaentes de los maperires us alza do y las culdue su sentido
Las imágenes fotográficas de Rodrigo Avila no escatiman la belleza simbólica de memorial. Por ultimo la Casa para la Memoria y Espacio Comunitario, Remanso de Paz, localizada en el municipio de Bello- Antioquia, es un edificio que exhala en su materialidad la reparación colectivas de las victimas por desapariciones forzosas, destrucción de edificaciones y las masacres, entendido que reparación colectiva es,según la JEP y el tratado de paz:

La reparación colectiva se refiere al conjunto de medidas de restitución, indemnización, rehabilitación satisfacción y garantia de no repeticion, a que tienen derecho las comunidades y las organizaciones o grupos sociales y políticos
riales y simbólicos.

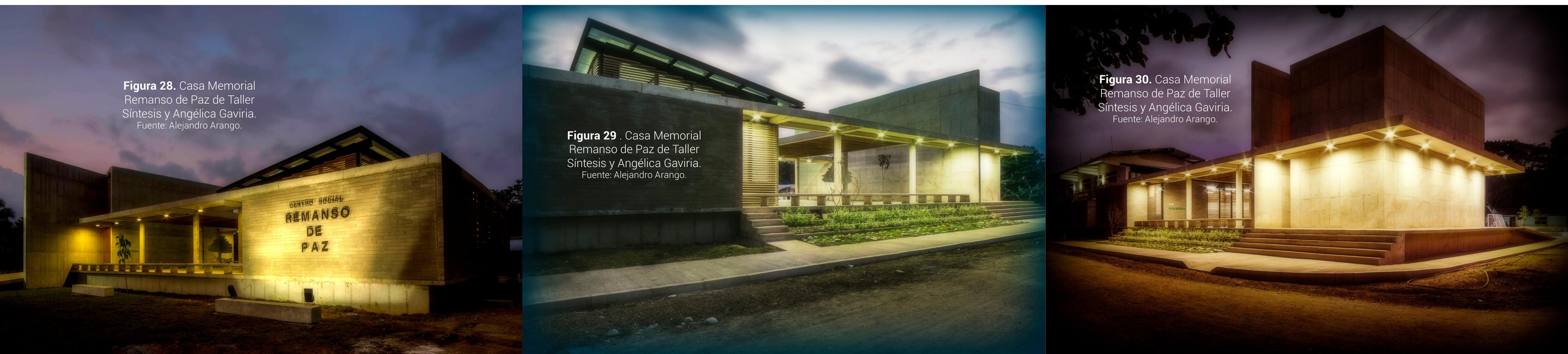


De esta forma se crea un vinculo entre la comunidad y la propuesta arquitectónica que desde su programa busca espacios de convivencia, de diversión y de recordación no para llorar a las victimas, sino para pensar que sus sacrificios no fueron en vano y se pueda de alguna forma crear tejido humano social en las nuevas generaciones del lugar para que estos hechos no se repitan nunca jamás. los arquitectos que diseñaron este centro fueron Taller Síntesis y Angélica Gaviria (Figura 28, Figura 29 y Figura 30).

\section{Conclusiones}

Queda claro que la arquitectura es un manifiesto, un texto que se lee desde su materialidad y como tal envía un mensaje que posee una sintaxis capaz de penetrar en el alma y en el corazón de todo ser humano que la habita, una piedra no solo es una piedra si en el lenguaje del arquitecto esa piedra forma parte de una comunidad que la arrojo por el barranco o se la quedo para dar inicio a un puente que permita cruzar ese barranco. la forma en la arquitectura no solo es matemática, su acierto o error puede ser interpretado por el arquitecto con composiciones armónicas o discrepantes, todo depende del concepto que el arquitecto implemente no por mero capricho sino por que de alguna forma quiere conectar la materia inerte de su obra con el cuerpo vivo de quien la habita y así colmarlo de emociones, sensaciones y sentimientos. El espacio no es solo un lugar vacio e inhóspito, para el arquitecto es un sitio estereofónico, con notas, acentuaciones y ritmos que cobran volumen, sustancia y movimiento para el desarrollo del ser humano en sus mas altos anhelos y deseos y se materializa para ser vivido, recorrido y gozado...dicho así, toda sociedad anhela de muchas maneras alcanzar paz que fue robada por la discordia, el conflicto será algo que convivirá con el ser humano siempre, aquel que fue liberado de la caja de Pandora; se quiere creer que solo la esperanza como consuelo final quedo atrapada en el cofre, por lo tanto es lo que la humanidad atesora cuando todos los males están dispersos en este mundo esperando algún día llegar a la utopía de una convivencia sana y justa entre nuestras sociedades contemporáneas. Mientras, se seguirán construyendo memoriales monumentales que envíen otro mensaje: lo que aquí ocurrió aquí se queda y no volverá a ocurrir ni aquí ni en ninguna otra parte, esperanzados que en un futuro los memoriales se construyan para celebrar y festeja la vida y no conmemorar la muerte. La arquitectura es un sistema de componentes que mas allá de la construcción que hace del ente arquitectónico un objeto visible y reconocible, es también una idea que surge de un imaginario colectivo interpretado por el arquitecto quien responde a una necesidad y a un discurso sobre todo de ciudad y de contexto. Resulta entonces entendible que procede de una comunidad indicando su grado de desarrollo y que tan próxima o no esta a esa utopía, el primer mundo, los países industrializados y las economías estables predominantes como Norteamérica, el grupo de la Comunidad Europea, los países del sol naciente, China, Japón y Corea y el gigante Ruso, tienen historias, han aprendido de sus historias, han preservado su legado y es claro que poseen todos ellos, 
un gran sentido de nación y de habitante de esa nación, eso los une y los hace fuertes, por lo tanto el recordar y no olvidar su pasado es un estimulo para en el presente ser mejores propendiendo a crear un futuro mas seguro y estable...no siempre será así, pero lo intentan, el tercer mundo y los países en vía de desarrollo o subdesarrollados por el contrario aun deben aprender a convivir como iguales, a respetar los derechos y deberes de todos y cada uno, en justicia y paridad, en igualdad y pluralidad, mientras esto no sea así, el conflicto prevalecerá y la paz será esquiva y renuente a recuperarse...por lo tanto seguirán habiendo victimas y victimarios, en honor a las victimas en necesario no olvidarlas y solo recordándolas se podrá lograr la no repetición y reparar el daño que si bien ya esta marcado, es al menos un acto de dignidad que debe imperar, El arte y la arquitectura pueden y son las herramientas para dignificar la existencia del ser humano Universalmente.

\section{REFERENCIAS}

Barbancho, J-R. (2014). Arte, Sociedad y Política: otras formas de protesta. ASRI, (6). 1-7. Recuperado de http://asri.eumed.net/6/arteprotesta.html

Canga, M. (2015). La opacidad de lo visible: apuntes sobre la imagen y la realidad. Opción, 31(4), 236-248. Recuperado de http://www.redalyc. org/html/310/31045569019/

Franco, L. (2009). Arquitectura, Psicología, Espacio e Individuo, AUS, (6), 12-17. Recuperado de http://www.redalyc.org/articulo.oa?id=28172 3479003
De Piccoll, G. (2019). La comunicación y el arte. las ilustraciones que se levantan para llevar un significado de inconformidad pacíficamente. Recuperado de https://enfoquecaribe. com/2019/02/la-comunicacion-y-el-arte-lasilustraciones-que-se-levantan-para-llevar-unsignificado-de-inconformidad-pacificamente/

De Piccoli, G. (2017). La espiritualidad en el arte, la esencia del ser humano en las mas grandiosas obras. Recuperado de https://enfoquecaribe. com/2017/11/la-espiritualidad-en-el-arte-laesencia-del-ser-humano-transformada-enlas-mas-grandiosas-obras/

De Piccoli, G. (2011). El ente arquitectónico contemporáneo: monumentalidad e imagen. Revista Móculo, Arquitectura CUC, 10(1), 237247. Recuperado de https://revistascientificas. cuc.edu.co/moduloarquitecturacuc/article/ download/.../pdf_7

DW. (septiembre 7,2018). TratadeBlancas: estrategias de combate contra esta esclavitud moderna. www.elmostrador.ch. Recuperado de https:// www.elmostrador.cl/braga/2018/09/07/tratade-blancas-estrategias-de-combate-contraesta-esclavitud-moderna/

El Tiempo. (enero 31, 2016). Conflictos Globales vistos desde la perspectiva del arte. El Tiempo [Online]. Recuperado de https://www.eltiempo. com/archivo/documento/CMS-16496618

Infobae, Efe. (octubre 14, 2019). El mapa del indice global del terrorismo 2017: hubo record de paises que sufrieron atentados. [Online]. Recuperado de https://www.infobae.com/ america/mundo/2017/11/15/el-mapa-delindice-global-de-terrorismo-2017-huborecord-de-paises-que-sufrieron-atentados/ 
Marin, E. (agosto 14, 2008). Monumento mujeres en la memoria y mujeres victimas de la represión politica. Arqa. [Online]. Recuperado de https:// arqa.com/arquitectura/monumento-mujeresen-la-memoria-mujeres-victimas-de-larepresion-politca.html

Notiamerica. (25 marzo, 2019). 23 de marzo: Día Internacional del recuerdo de las victimas dela esclavitud, $i$ Por que se conmemora hoy? www.notiamerica.com. [Online]. Recuperado de https://www.notimerica.com/sociedad/ noticia-25-marzo-dia-internacionalrecuerdo-victimas-esclavitud-conmemorahoy-20190325005933.html

Pacheco, R. (agosto 13, 2002). 60 Millones, los indígenas muertos tras la conquista. Cronica. com.mex. [Online]. Recuperado de http://www. cronica.com.mx/notas/2002/24297.html

Padovanet. (ottobre 2, 2018). Monumento "Memoria e Luce". [Online]. Recuperado de http://www. padovanet.it/informazione/monumentomemoria-e-luce
Portafolio. (abril 9, 2017). 8.376.463: las victimas del conflicto armado en Colombia. Portafolio. [Online]. Recuperado de https://www. portafolio.co/economia/gobierno/el-numerode-victimas-del-conflicto-armado-encolombia-504833

Proyectobaq. (mayo 5, 2017). Memorial a las victimas de la violencia en México. En, J. Gaeta \& L. Sprinngall, Teoría, Historia y Critica del Urbanismo y el Paisaje (Capítulo México). Recuperado de http:// arquitecturapanamericana.com/memorial-alas-victimas-de-la-violencia-en-mexico/

Wikiarquitectura. (N/A). Museo Memorial 11/S. [Online].Recuperado de: https:// es.wikiarquitectura.com/edificio/museomemorial-11s/ 
Giovanni Giuseppe De Piccoli Córdoba es Historiógrafo, Especialista en Restauración y Conservación de Bienes e Inmuebles, Máster en Visual Communication-Atlantic International University- Grupo de Investigación Ginvearqui.

Coordinador de Énfasis en Territorio, Bioclimática y Patrimonio y Electivas.de la Facultad de Arquitectura en la Universidad Santo Tomas, Seccional Bucaramanga (Colombia). 